HID 40 (2013)

\title{
TÉRMINOS DESPOBLADOS EN LA TIERRA DE CUENCA: UN PROBLEMA DE ORGANIZACIÓN DEL TERRITORIO Y ARTICULACIÓN SOCIAL EN EL SIGLO XV ${ }^{1}$.
}

\author{
DEPOPULATED BOUNDARIES IN THE LAND OF CUENCA: \\ A PROBLEM OF TERRITORY ORGANIZATION AND SOCIAL \\ ARTICULATION IN THE $15^{\mathrm{TH}}$ CENTURY.
}

\author{
José María SÁnchez Benito \\ Universidad Autónoma de Madrid \\ josemaria.sanchez@uam.es
}

RESUMEN: Siendo conscientes de la gran complejidad que presentan los despoblados bajomedievales, en el presente artículo se ofrece el estudio de un caso -la tierra de Cuenca-, a fin de analizar el fenómeno conjugando toda suerte de aspectos geográficos, económicos y sobre todo sociales. De este modo, el objetivo último del trabajo no se limita a la organización del territorio sino que va más allá, intentando profundizar en los diferentes intereses y grupos sociales que actuaban en los espacios rurales dependientes de las ciudades realengas.

Palabras Clave: Aldeas, campesinado, concejo, despoblados, élite ciudadana, propiedades agrarias, sociedad rural, Cuenca, siglo XV.

ABSTRACT: Aware of the enormous complexity that the depopulated boundaries in the Late Middle Ages show, a case of study is offered in the present article -the land of Cuenca-, in order to analyze the phenomenon conjugating all sorts of geographical, economical and mainly social aspects. The last aim does not confine to the organization of the territory but it goes further away, trying to go more deeply into the different interests and social groups that acted in the rural areas dependent on the kingly cities.

KEYwORDS: Villages, peasantry, council, depopulated boundaries, city elite, agricultural properties, rural society, Cuenca, 15 th century.

1. Este artículo se ha realizado en el marco del proyecto: Fundamentos de identidad politica: La construcción de identidades políticas urbanas en la Península Ibérica en el tránsito a la Modernidad, financiado por la Dirección General de Investigación y Gestión del Plan Nacional de I+D+I, referencia HAR2009-08946.

Abreviaturas utilizadas: Archivo de la Catedral de Cuenca = ACC; Archivo General de Simancas = AGS; Archivo Municipal de Cuenca = AMC; Registro General del Sello = RGS 


\section{INTRODUCCIÓN}

El estudio de los despoblados bajomedievales se inició en España hace décadas de la mano de Nicolás Cabrillana. Desde entonces, al avanzar la investigación, se ha puesto de manifiesto que se trata de un fenómeno poliédrico, condicionado por multitud de factores de la más diversa índole e incluso contradictorios. Por lo tanto, si en varias ocasiones se han propuesto explicaciones unilaterales, partiendo de evidencias encontradas en tal o cual lugar, pronto se vio que la complejidad del asunto se resistía a ceñirse a ellas.

Siendo perfectamente conscientes de lo dicho, en el presente artículo se presenta un caso, la tierra de Cuenca, que no solamente constituye un ejemplo bien documentado sino que presenta unas características que lo hacen particularmente interesante para poner en evidencia dicha complejidad, así como para ulteriores comparaciones con otros ámbitos regionales. De esta manera, los objetivos del trabajo se resumen del siguiente modo:

a. Analizar el proceso de despoblación conjugando toda suerte de aspectos geográficos, económicos y sobre todo sociales, porque no solamente se desea comprender mejor la organización del territorio sino que nuestras aspiraciones van más allá, intentando mostrar los diferentes intereses que repercutían sobre los recursos naturales y las formas del hábitat.

b. Aclarar en lo posible causas y peculiaridades, prestando especial atención a la intermitencia que caracteriza la evolución de la mayoría de los despoblados.

c. En definitiva, el objetivo último consiste en arrojar luz sobre las formas de vida en el mundo rural y, muy especialmente, avanzar en el estudio de la sociedad que vivía en los espacios realengos y sus tensiones.

Para formarnos una idea preliminar, adelantaremos que a lo largo del siglo $\mathrm{XV}$ tuvieron en algún momento la consideración de despoblados más de sesenta lugares de la tierra, por encima del $44 \%$ del total. Ciertamente unas cifras escuetas, por más que puedan parecer cuantiosas, no dicen mucho y, por lo tanto, lo primero que tenemos que hacer es concretar. De este modo, sin pretender una definición pormenorizada del concepto despoblado, es preciso señalar que para que una localidad se considerase jurídicamente como tal no era necesario que perdiese todos sus habitantes y quedase completamente yerma. Como es lógico las propiedades privadas seguían manteniendo todo su valor, las tierras se seguían cultivando en muchos casos y, como tendremos ocasión de comprobar, la mayoría no se vaciaban del todo sino que mantenían unos cuantos habitantes. Además, esos habitantes no siempre tenían la condición de vecinos, pues muchas veces eran renteros o trabajadores de las heredades allí existentes y nunca alcanzaban tal condición e incluso ni siquiera se lo proponían. De manera que resulta perfectamente válida la apreciación de Reglero: "ni todos los hábitats abandonados son tenidos por ta- 
les, ni se considera necesario el abandono total del hábitat para calificar un lugar despoblado"'.

Siendo esto así, se explica perfectamente que para el concejo de Cuenca solo tuviera dicha condición el lugar que contase con menos de diez vecinos -alguna vez cinco-, sin orden de pueblo ${ }^{3}$. Por consiguiente, se tenía por despoblado aquel lugar en el que no había propiamente comunidad y en consecuencia no había concejo, perdiendo su sentido la organización espacial que habitualmente tenían los términos aldeanos -dehesas boyales, ejidos, etc.- y que el concejo rural, ahora inexistente, tenía que mantener ${ }^{4}$. Así pues, debemos tener muy presente que lo importante para que un lugar se entendiese despoblado no era la presencia o no de habitantes, sino de vecinos pecheros. De suerte que la pecha-la contribución del lugar y su gente a las cargas fiscales de la tierra- era el criterio determinante.

\section{Cronología y localización de los Despoblados}

Todos los investigadores de la despoblación son perfectamente conscientes de la dificultad que encierra la cronología de estos procesos ${ }^{5}$. En el caso de Cuenca, que nos ocupa en este artículo, es menester subrayar que casi siempre se producen de manera evolutiva y muy lenta, a través de largas transiciones llenas de altibajos y recovecos, cuya conclusión puede retrasarse durante muchos años o ni siquiera producirse, porque hay bastantes despoblados del siglo XV que, en la actualidad, están vivos. Por el contrario, es difícil encontrar abandonos ocurridos bruscamente, de manera, digamos, catastrófica.

2. C. REGLERO DE LA FUENTE. "Los despoblados bajomedievales en los Montes de Torozos: jerarquización del poblamiento y coyuntura económica”, Edad Media. Rev. de Historia 1 (1998), p. 185 .

3. Según la expresión que utilizan las ordenanzas vigentes a finales del siglo XV, Archivo Municipal de Cuenca, leg. 44-3. En Soria, por ejemplo, la cifra era cinco vecinos, por debajo de los cuales el término se consideraba "deraygado" y se incorporaba a los realengos, M. DIAGO. "Los términos despoblados en las comunidades de villa y tierra del Sistema Ibérico castellano a finales de la Edad Media", Hispania 178 (1991), p. 471. Este artículo está en el punto de partida del presente trabajo, Hace pocos años J. CLEMENTE RAMOS presentó la historia y características de una modesta localidad extremeña que terminó despoblándose, en su artículo "Martín Sancho (siglos XIV-XVI). Un despoblado bajomedieval en la tierra de Medellín”, Hispania LXVI/223 (2006), pp. 483-500. El estudio arqueológico de un lugar alcarreño bastante próximo en A.M. DÍAZ LEÓN, M. GÓMEZ BRAVO, I. MARTÍNEZ MARTÍN. "El despoblado medieval de La Golosa (Berninches, Guadalajara). I campaña arqueológica (1991)", Wad al Hayara 20 (1993), pp. 45-64. Consideraciones sobre los fenómenos que nos ocupan en un marco regional, en mi artículo "Sobre la organización de los territorios concejiles al sur del Sistema Central: ciudades y aldeas en los siglos XIV y XV", La Historia peninsular en los espacios de frontera: las "Extremaduras históricas" y la "Transierra" (siglos XI-XV). Cáceres-Murcia, 2012, pp. 143-48.

4. Sobre la organización de un término aldeano en la tierra de Cuenca ver mi artículo: "Una aldea realenga y su concejo en tiempos de los Reyes Católicos: Fuentes, tierra de Cuenca", Historia, Instituciones, Documentos 32 (2005), pp. 289-95.

5. N. CABRILlANA. "Los despoblados en Castilla la Vieja", Hispania 31 (1971), p. 501, decía que era el problema más arduo en el estudio de los despoblados. 
Si centramos nuestra atención en estos últimos, forzoso será aludir a las guerras. Por supuesto, no podemos entrar ahora en detalles, pero, desde luego, fueron muy frecuentes en el siglo XV conquense. Baste decir que reiteradamente alcanzaron a la totalidad del territorio y produjeron no pocos daños materiales, así como quiebras en el cobro de los impuestos, y en diversas ocasiones obligaron a la gente a huir de sus pueblos. Podemos constatar estos hechos en 1430, por ejemplo, cuando el concejo ciudadano reconocía que muchos moradores de la tierra, cercanos a Aragón, habían tenido que abandonar sus casas, dificultándose enormemente las tareas encaminadas a la cobranza de las rentas fiscales ${ }^{6}$. Del mismo modo, las cuentas elaboradas en el otoño de 1432 para repartir el pecho que cada año pagaban los aldeanos dan a entender que Reillo, lugar inmediato a los límites orientales de la jurisdicción, quedó despoblado como consecuencia de la guerra que venía desde Aragón. Así que hemos de aceptar que tales huidas constituyen un hecho cierto y suficientemente extendido, y que con frecuencia la violencia perturbó de manera severa la cotidianeidad del mundo serrano ${ }^{7}$.

Ahora bien, inmediatamente tenemos que introducir matices. En el caso de Reillo, que acabamos de mencionar, no se observa cambio alguno en el montante de sus obligaciones fiscales durante los años inmediatamente posteriores al citado y, por lo tanto, habrá que entender que la marcha de sus vecinos fue momentánea y seguramente incompleta. En otros pueblos, por ejemplo del sexmo de Arcas, sí se observan reducciones en las cantidades a pagar a lo largo del decenio de los años treinta, pero al comparar las cifras de los diferentes pueblos los resultados son dispares y en alguno de los que se vieron más afectados por el conflicto no hubo bajada impositiva alguna ${ }^{8}$. En cambio, a fines de siglo hay testimonios que podrían indicar lo contrario. Efectivamente, en 1494 se afirma que el lugar de Yémeda se había despoblado a consecuencia de las guerras unos cincuenta años antes. Es decir, se aludía, sin duda, a los graves conflictos acaecidos entre 1447 y 50 en cuyo transcurso se produjeron grandes destrucciones en el corazón mismo de la ciudad. Viendo la trayectoria de este lugar se comprueba que no vuelve a aparecer en los repartimientos fiscales con posterioridad a 1448, y ya en 1430 hay menciones que lo consideran despoblado 9 . Se trata de un pueblo débil, en el que la gran propiedad tuvo siempre un peso muy importante y tanto en la primera mitad del siglo XV como después, a lo largo de la Edad Moderna y Contemporánea, presenta una trayectoria oscilante hasta llegar a la actualidad, porque subsiste hoy día. Éste es

6. AMC, leg. $187-5$, f. 14 r-15r.

7. Las contabilidades de 1431, 32 y 35 en AMC, leg. 188-2, f. 1r-13r; 188-3, f. 1r-11r; 188-5, f. $1 \mathrm{r}-13 \mathrm{r}$.

8. Se refiere a la limitada incidencia de la guerra en el abandono de pueblos, C. REGLERO DE LA FUENTE. "Los despoblados bajomedievales en los Montes de Torozos", p. 189. He tenido oportunidad de tratar los efectos de la guerra en mis trabajos recientes "Violencia y pugna política. Estudio de sus repercusiones en el mundo urbano a través del caso de Cuenca (siglo XV)", Studia Historica. Historia Medieval 30 (2012), pp. 237-62, y "Violencia y señorialización del territorio realengo en el siglo XV. Datos y consideraciones en el caso de Cuenca", todavía en prensa.

9. Archivo General de Simancas, Registro General del Sello, 1494-XI, f. 302; AMC, leg. 64-1 y $187-5$, f. 51 r. 
un comportamiento muy característico en la tierra de Cuenca y aunque en algún momento pudieran incidir circunstancias extraordinarias, habrá que pensar más bien en causas mucho menos coyunturales para explicar su trayectoria. En cualquier caso, el despoblamiento de la tierra es un argumento típico con el que cabía dar mayor vigor a toda suerte de quejas y no es raro su uso por parte del concejo a la hora de protestar por la presión nobiliaria sobre la jurisdicción ciudadana ${ }^{10}$.

De forma que dejando a un lado las desapariciones catastróficas, cuyo impacto a medio y largo plazo parece simplemente nulo o, en todo caso, muy reducido, y aceptando que las posibilidades que tenemos para fijar la cronología de los abandonos son pocas y dificultosas, retrocederemos en el tiempo con el fin de mostrar el desarrollo temporal del proceso de despoblación en la tierra de Cuenca. A tal fin, cabría hablar de una primera etapa, cuyos perfiles no es posible concretar bien pero que se inicia ya en el siglo XIII y para la cual, ciertamente, podemos alegar muy pocos ejemplos. Sería el caso probablemente de Albaladejo, al lado mismo de la ciudad; Cabeza de la Mota, al sur; y los pueblos serranos Huertabellida y Morelejo. Los dos primeros están directamente relacionados con grandes propiedades de carácter antiguo, y de los siguientes apenas hay información, salvo indicar que Huertabellida se cita en los primeros tiempos de la jurisdicción conquense y solamente se vuelve a mencionar su nombre, ya como despoblado, en fechas tardías, mientras que Morelejo estaba completamente vacío al iniciarse el siglo XV ${ }^{11}$. Aparte lo dicho, hay algunos núcleos que aparecen escasamente durante el siglo XIV en ocasión del pago de los diezmos eclesiásticos, pero con respecto a los cuales no sabemos otra cosa que la ulterior permanencia del topónimo como dehesa o gran heredad y uno de ellos ni siquiera eso. Sirve como ejemplo Cañizares, que ya no figura en las relaciones decimales en 1399 y que después, y aún hoy, se mantiene como dehesa; también Torrepineda; Zarzoso, que tampoco aparece al pagar los diezmos de 1399 y después se cita varias veces como despoblado. Hay que destacar que casi todos están en el sexmo de Arcas, tanto en las proximidades de la ciudad como hacia el este de la referida demarcación, en una zona bastante montuosa. De todos ellos no hay ninguna noticia como poblaciones vivas con posterioridad al siglo XIV y, por lo tanto, corresponderían también a esta fase antigua del proceso que estamos estudiando. Lo que ocurre es que en realidad no son verdaderos pueblos abandonados sino lo que se denomina falsos despoblados. Con esta expresión, realmente adecuada, se designa a lugares que nunca se consolidaron como aldeas y que no fueron más que granjas o pequeños hábitats, seguramente no más

10. Se invocó en 1483, por ejemplo, cuando Pedro Carrillo de Albornoz, partiendo de ciertas torres que tenía tomadas, intentó hacerse con el señorío de varias poblaciones: Alcantud, Cañizares y Fuertescusa. Ni que decir tiene que si bien tales presiones eran ciertas no sirvieron para vaciar ninguno de los tres pueblos. AMC, leg. 204-3, f. 87v-88r. Podrían alegarse muchos más casos.

11. En el área toledana no parece haber indicios de despoblamiento antes de la mitad del siglo XIV, J.-P. MOLENAT. "Une mutation du paisaje rural: villages désertés en Nouvelle Castille, XIIe-XVIe siècles”, en Le paisaje rural: realités et representations. X Colloque des historiens médiévistes, 1979, p. 202, aunque luego la cifra resulta bastante elevada. Para contextualizar adecuadamente el fenómeno en el ámbito de Toledo, ver la obra del mismo autor Campagnes et Monts de Tolède du XIIême au XVème siècle. Madrid, 1997, especialmente pp. 421-33. 
que poblamiento disperso, aunque en algún momento se quisiera asociar a alguno de ellos la palabra aldea. En todo caso, dieron lugar a términos bien delimitados ${ }^{12}$ $\mathrm{y}$, en su momento, convenientemente adehesados en casi todos los casos.

\section{MAPA}

TÉrminos Despoblados de la tierra de CuencA

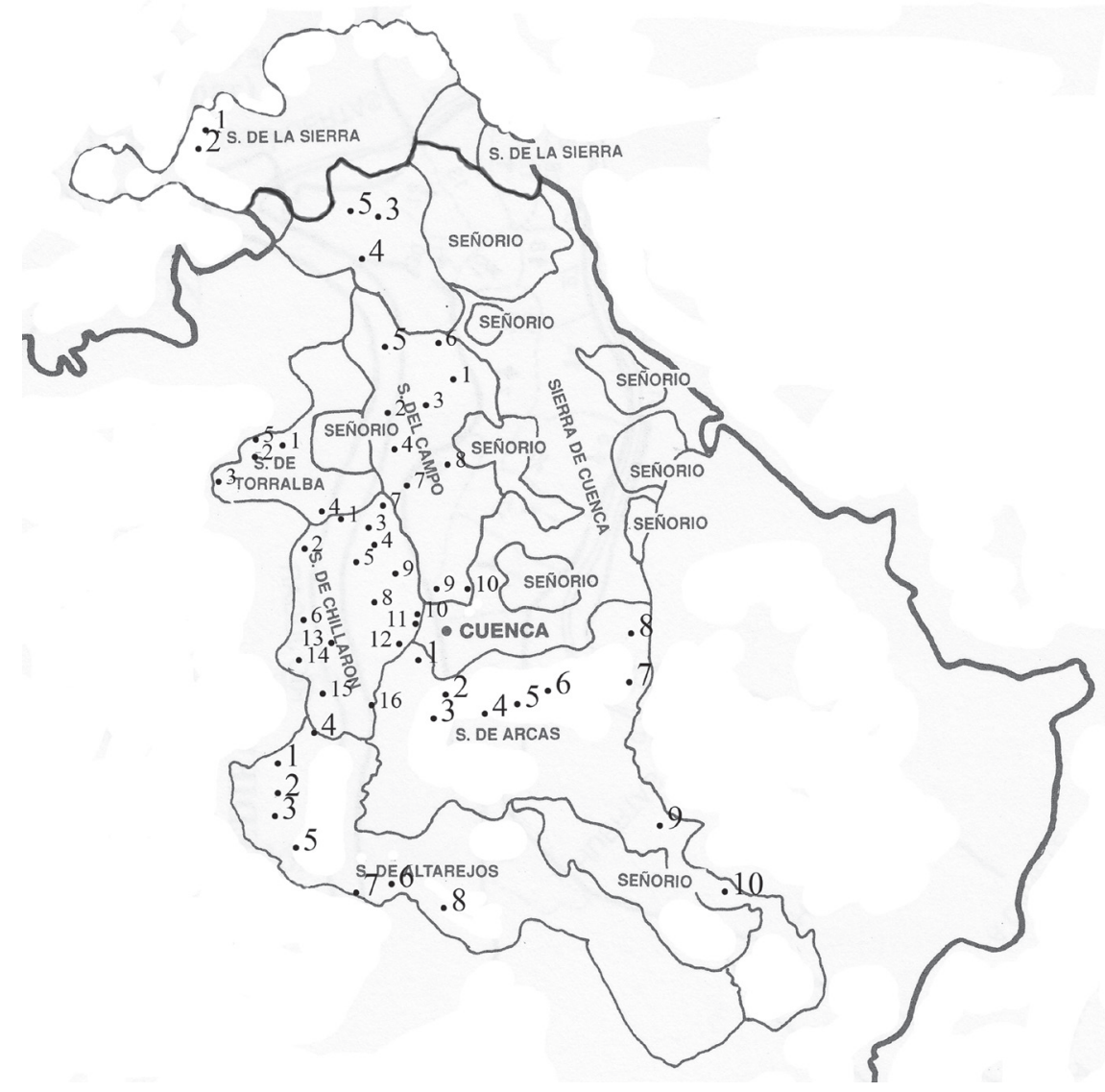

12. A diferencia de numerosas granjas existentes alrededor de la ciudad, a las que no se reconocía término específico. 
SEXMO DE LA SIERRA:

1 Murillejo

2 Solana

3 Huertabellida

4 Palomares

5 Hoyos
SEXMO DE TORRALBA:

1 Castillo Albaráñez

2 Olmedilla Eliz

3 Fuentesbuenas

4 Valdecañas

5 Perales
SEXMO DEL CAMPO

1 Arcos de la Sierra

2 Villaseca

3 Pajares

4 Torrecilla

5 Titos

6 Fresneda de la Sierra

7 La Losilla

8 Villarejo

9 Embid

10 Verdelpino

SEXMO DE ALTAREJOS

1 Malpesa

2 Cañada del Manzano

3 Villarejo Periesteban

4 Las Tejas

5 Aldehuela

6 Villaverde

7 La Mota

8 Mezquitas

8 Jabaguilla

9 Tondillos

10 Nohales

11 Albaladejo

12 Colliguilla

13 Fuenteferruz

14 Cabrejas

15 Hortizuela

16 La Osilla

En una segunda fase situaremos aquellos lugares que quedaron definitivamente vacíos en el transcurso del siglo XV. No he encontrado más que seis -Aldehuela, La Losilla, Tondillos, Palomares ${ }^{13}$, Palomarejos y Solana- y los tres últimos están al norte, en el sexmo de la Sierra. Bien es verdad que tanto en estos casos como en los que yermaron con posterioridad, es lo normal que quedasen caseríos de mayores o menores proporciones, todavía hoy presentes casi siempre. Así que, en conclusión, los núcleos que quedaron vacíos en el transcurso de la Edad Media y nunca volvieron a recobrar su extinguida vitalidad son realmente pocos. Sumando los que hemos considerado despoblados antiguos y los que quedaron abandonados en el siglo XV -y sin contar, por supuesto, los falsos despoblados- no van más allá del 7\% del total de lugares surgidos en la tierra. Además, es significativo que la mayor parte de estos abandonos medievales se concentran en el referido sexmo

13. Aldehuela figura como lugar avenido a efectos fiscales en los años treinta y no vuelve a aparecer. La Losilla debió extinguirse hacia la mitad del siglo o seguramente antes. Tondillos, término redondo de la Orden de Santiago, desaparecería como pueblo desde la mitad del siglo XV o antes, igual que Palomares. 
septentrional. De manera que la mayoría de las muchas aldeas constituidas durante la repoblación, aunque fuesen calificadas como despoblados, sobrevivieron hasta bien entrado el siglo XVI. Después, algunas fueron extinguiéndose paulatinamente y otras lograron consolidarse lo suficiente como para llegar a nuestros tiem$\operatorname{pos}^{14}$. No hay que olvidar que las que se han mantenido hasta la actualidad llegan nada menos que al $43 \%$ del total de los despoblados del siglo XV -siempre sin contar las diversas formas de poblamiento disperso- y en buena parte de la tierra -sexmos de Arcas, Campo y Torralba- son la mayoría. Por lo tanto, no es posible buscar las causas en una coyuntura demográfica desfavorable, cual pudo ser la del siglo $\mathrm{XIV}^{15}$, y la inmensa mayor parte sufrieron procesos de carácter evolutivo e intermitente, cuya complejidad tendremos que esclarecer en lo posible ${ }^{16}$.

La tierra de la ciudad conquense, que se desarrolla en sentido norte-sur apoyándose en el trazado del Sistema Ibérico, tenía una organización dúplice, distinguiendo los términos de las aldeas agrupados en seis sexmos y, por otra parte, la Sierra de Cuenca, gran espacio dedicado a la explotación ganadera y montaraz. La red de poblamiento rural que vamos a encontrar debe entenderse en el marco de las siguientes coordenadas: a) limitación estructural del número de habitantes, aunque en el siglo XV el crecimiento demográfico es indiscutible; y b) debilidad extrema de la mayor parte de las muchas aldeas que surgieron en la repoblación ${ }^{17}$.

Así las cosas, vamos a enumerar los seis sexmos a fin de penetrar en la cuestión propuesta y enmarcar el fenómeno en la estructura del poblamiento ${ }^{18}$. Si co-

14. Cierto es que se mantienen en la actualidad de forma harto precaria, quizá salvo Nohales que por su cercanía a la ciudad conquense ha visto surgir pequeñas urbanizaciones en los últimos años.

15. Así lo señala, entre otros, J. CLEMENTE RAMOS en los primeros párrafos de su artículo "Martín Sancho", p. 484.

16. Alude a esta complejidad, C. REGLERO DE LA FUENTE. "Los despoblados bajomedievales en los Montes de Torozos", p. 193-96. Este autor establece tres fases en el proceso de despoblamiento que observa en su zona de estudio, aunque se da cuenta perfectamente de las dificultades que se presentan para ello (abandonos temporales, etc.), pp. 186-87.

17. Sobre la morfología de dichas aldeas ver J.M. SÁNCHEZ BENITO. Las tierras de Cuenca y Huete en el siglo XIV. Historia económica. Cuenca, 1994, pp. 77-79; y para la siguiente centuria "Una aldea realenga y su concejo en tiempos de los Reyes Católicos”, pp. 287-89.

18. Se hace una aproximación al poblamiento medieval en la tierra de Cuenca en mi libro citado en la nota anterior Las tierras de Cuenca y Huete en el siglo XIV, pp. 31-33. Para la realización del análisis que sigue a continuación han servido de apoyo todos los repartimientos del pecho de San Miguel incluidos en las actas municipales conquenses del siglo $\mathrm{XV}$, así como los libros de rentas más antiguos conservados en el Archivo de la Catedral, desde el año 1338 a 1400. De la época moderna varios vecindarios estudiados por M. GESTEIRO ARAUJO, M.L. VICENTE LEGAZPI. "La población de la diócesis de Cuenca a mediados del siglo XVIII", Lope de Barrientos. Seminario de Cultura, 4 (2011), pp. 51-85. También Censo de 1787 "Floridablanca". Cuenca, Instituto Nacional de Estadística, Madrid, 1987, y algunos datos procedentes del Catastro de Ensenada (Respuestas Generales: Cuenca), que me ha facilitado $\mathrm{M}^{\mathrm{a}}$ Luz Vicente Legazpi. Igualmente se ha consultado el Diccionario geográfico-estadístico-histórico de España y sus posesiones de Ultramar, Madrid, 1845-50, de PASCUAL MADOZ, en la edición facsímil referente a Castilla-La Mancha que con estudio introductorio de Isidro Sánchez Sánchez, se publicó en 1987. Asimismo, ha tenido cierta utilidad la mucha erudición contenida en Cuenca. Guía Larrañaga. Cuenca, 1966, debida a J. LARRAÑAGA MENDÍA. Por supuesto, y ya para acabar estas prolongadas referencias, se ha recurrido continuamente a través de Internet al SIGNA del Instituto Geográfico Nacional. 
menzamos por el norte, el sexmo de la Sierra presenta seis entidades de población que en el siglo XV cabe calificar como despoblados, sea por haberse quedado vacíos o por tener tal consideración legal. En este espacio las distintas localidades existentes siguen una jerarquización muy clara a partir de tres centros principales (Recuenco, Villanueva de Alcorón y Zahorejas), situados en el centro de la demarcación y mucho más sólidos que los demás; a continuación, varios núcleos intermedios (Alcantud, Cañizares, Fuertescusa, Poveda, Pozuelo, La Puerta); y un tercer nivel formado por los más pequeños. No obstante en esta demarcación hay que tener en cuenta que las condiciones topográficas no permiten la formación de hábitats en gran parte del territorio, y es preciso diferenciar con nitidez el sector occidental, donde las aldeas están más cerca unas de otras y el paisaje tiene características alcarreñas, frente al resto. En tales coordenadas los despoblados se ubican en el citado sector occidental (Solana y Murillejo), mientras que Huertabellida, Morelejo y Palomares están bastante próximos entre sí e insertos en una topografía muy difícil. Por lo que se refiere a estos últimos, las limitaciones del medio y, en el caso concreto de Palomares, la proximidad de un lugar más importante cual es Cañizares, son factores a considerar para entender el fenómeno de la despoblación que, por cierto, en todos ellos fue completa. En un párrafo anterior acabamos de decir que es en este sexmo donde más poblaciones se vaciaron totalmente durante el período medieval, quedando una sola, que es Murillejo, con capacidad para recobrar fuerza en etapas históricas posteriores y llegar con vida hasta la actualidad. Murillejo era pues una aldea muy pequeña, en cuya evolución parece tener peso la gran propiedad y en la cual constan intentos de repoblación. Ejemplifica muy bien un proceso que no será precisamente excepcional.

Descendiendo hacia el sur llegamos a los sexmos de Torralba, El Campo y Chillarón. El de Torralba no solo es el más pequeño sino que además presenta una peculiaridad cual es que sus principales centros -y en particular la villa del mismo nombre- fueron prontamente señorializados y quedaron separados del resto de la tierra. Por ese motivo es la demarcación de inferiores dimensiones y, a falta de su cabeza natural, incluye unos cuantos pueblos bastante modestos y separados por distancias cortas. También en el centro de la tierra, el sexmo del Campo confinaba por el sur directamente con la ciudad y hacia el este con las grandes extensiones comunales de la Sierra. En ambas demarcaciones se observa una estructura de poblamiento articulada por gran cantidad de núcleos aprovechando las tierras cultivables que se extienden en las proximidades de los cursos de agua. La jerarquización del poblamiento es, por tanto, escasa y los que ocupan el escalón inferior devienen despoblados. Durante el siglo XV son seis en Torralba, situados hacia el oeste en un paisaje propiamente alcarreño, en tanto que en el Campo se cuentan ocho, dos de los cuales -Embid y Verdelpino- están muy cerca del núcleo urbano y es seguro que esta proximidad cuenta mucho en su destino ${ }^{19}$. De manera

19. C. REGLERO DE LA FUENTE. "Los despoblados bajomedievales en los Montes de Torozos", p. 203. Se ha fijado este autor en la amplitud que tiene el radio de acción de villas y ciudades, de forma que alrededor de ellas surge una orla de despoblados. Desde luego, cabe afirmar que este hecho se produce en torno a Cuenca. 
que tendremos que fijarnos en la debilidad de los núcleos afectados y, por lo que se refiere a la cronología, en la demarcación de Torralba ya no hay más que un despoblado temprano -Bolliguilla-, en tanto que el resto son pueblos pequeños o muy pequeños que de manera intermitente consiguen sobrevivir hasta el final del siglo XV, y todos, salvo Perales, han llegado a nuestra época. La demarcación vecina -sexmo del Campo- incluye algún lugar realmente ínfimo, como era La Losilla, definitivamente yermo, pero la mayoría de los casos responden también al modelo intermitente.

Donde estas características alcanzan su culminación es en el sexmo cercano de Chillarón, hacia el oeste. Este distrito, quebrado y montuoso, confinaba con la ciudad y es el que tiene un mayor número de núcleos y también de despoblados: son 32 y 21 respectivamente, y estos últimos se reparten de manera bastante uniforme, a veces muy cerca unos de otros. Casi no hace falta añadir que todos los pueblos son muy reducidos y, salvo los situados a lo largo del río Chillarón, tienen poca tierra de cultivo. Tampoco aquí puede afirmarse que el peso de aldeas más importantes obstaculizara el desarrollo de otras y con facilidad se observa que son multitud las que siempre están en el mismo umbral de la despoblación y, por cierto, no solo las que ocupan posiciones más montañosas. Al igual que en los dos sexmos precedentes, también predomina el modelo intermitente que ya hemos encontrado antes, siguiendo dos modalidades: aquellos lugares que tras evolucionar con toda suerte de altibajos siguen vivos al final del siglo XV, o los que habían desaparecido en dicho momento y luego fueron capaces de retornar aunque sea modestamente. En cualquier caso, no hay que olvidar que incluso en las condiciones existentes en estos sexmos centrales se consolidaron determinados pueblos más firmes. No serán grandes, pero destacan en la débil estructura de poblamiento propia de la zona.

El panorama empieza a cambiar algo cuando avanzamos hacia el mediodía, a través de los sexmos de Arcas, colindante con la ciudad, y Altarejos. El primero de ambos presenta múltiples núcleos cerca de Cuenca, y hacia el este y el sur la distancia entre los pueblos tiende a aumentar, si bien es verdad que allí abundan zonas de montaña en las que es difícil el desarrollo de hábitats. El segundo muestra también el creciente alejamiento de los pueblos a medida que se avanza hacia el sur. A diferencia de lo que veíamos anteriormente, encontramos ahora localidades que destacan con claridad, como es el caso de Fuentes en el sexmo de Arcas; y si miramos hacia Altarejos comprobamos que la jerarquización es muy evidente, partiendo de una población principal -La Parrilla-, seguida por Campillo y Almodóvar, que son las más meridionales; a continuación hay un núcleo intermedio, Valera de Yuso; y finalmente muchos lugares pequeños, los últimos de los cuales serán los despoblados. Por debajo, en un último escalón, pueden verse formas de poblamiento disperso, particularmente en el este, y hacia el sur hay lugares que figuran de manera muy esporádica en los registros fiscales pero nunca constituyeron verdaderos pueblos y entran pues en la categoría falsos despoblados ${ }^{20}$. En este

20. Sería el caso de Molino Castellar o también, aunque de otra manera, Las Tejas, donde se constituyó un adehesamiento. 
marco, y centrándonos ya propiamente en los despoblados, las cifras que arrojan ambos sexmos son parecidas, once y nueve respectivamente, y se sitúan hacia el este - en los límites con la tierra de la villa de Moya- o en los alrededores de la ciudad, por lo que se refiere a la demarcación de Arcas; en tanto que en Altarejos están enclavados en el centro y norte del distrito, casi siempre al lado de los linderos del mismo. En definitiva, entre los lugares calificados como despoblados se cuentan verdaderas aldeas, muy condicionadas por la presencia de grandes heredamientos - La Cierva y La Melgosa en Arcas, Villarejo de Periesteban en Altarejos-, y mayor cantidad de lugares muy pequeños. Al contrario que en el centro de la tierra conquense aquí sí puede observarse la proximidad de localidades de mayor firmeza, cual es el caso de Fuentes, alrededor de la cual orbitaban Atalaya y Las Zomas ${ }^{21}$.

Como hemos dicho, la mayoría de los lugares que en algún momento se consideraron despoblados siguen una trayectoria intermitente, de modo que unas veces figuran en los repartimientos y otras desaparecen, de la misma manera que en ocasiones se los denomina utilizando la palaba despoblado y en otros momentos no se hace así. Ocurre, sin embargo, que estas trayectorias tan poco rectilíneas son difíciles de explicar y ello principalmente porque en el seno de las posesiones que tenían los herederos más fuertes actuaban muchos trabajadores que no eran considerados pecheros: mayordomos excusados, braceros foráneos, renteros que no pagaban mediante los procedimientos ordinarios de percepción fiscal, etc. Las situaciones personales podían ser diversas pero lo importante es que, de alguna manera, quedaban ocultos unos individuos que aun siendo pocos tenían permanencia en unos lugares en apariencia solitarios. También es verdad que muchos pueblos conquenses eran ínfimos, especialmente en el centro de la tierra, y por ello cualquier oscilación podía afectar a su continuidad. Claro que junto a estos lugares mínimos se dio la consideración de despoblado a otros mucho más sólidos, en los cuales casi todo el mundo estaba inserto en grandes propiedades y, por lo tanto, no había pecheros. Por otra parte, aunque resulta del todo imposible hacer cálculos precisos, no hay que excluir de ninguna manera que se produjeran abandonos temporales sin que por ello las tierras, o parte de ellas, dejasen de cultivarse. Efectivamente, un pueblo siempre escaso en población y con una consistencia constructiva pequeña, podía quedar vacío de habitantes permanentes durante períodos de tiempo y no por ello se esfumaba la actividad ${ }^{22}$. Hay que añadir que la formación de estos despoblados no va unida a la mejor o peor calidad de los suelos. Así que teniendo en cuenta los diversos factores que han quedado expuestos, concluiremos que el nivel más bajo de la estructura de poblamiento conquense presenta una gran inestabilidad en la época que nos ocupa.

21. Atalaya y Las Zomas orbitan literalmente alrededor de Fuentes. Comprobé este aspecto en mi artículo "Una aldea realenga y su concejo en tiempos de los Reyes Católicos", p. 291 y nota 9. En el mismo sexmo puede observarse lo mismo en torno a Arcas, Cañada del Hoyo y Villar de Olaya.

22. Aunque es imposible precisar, este debe ser el caso, entre otros, de Malpesa (sexmo de Altarejos), Arguisuelas (Arcas), Cañamarejos, Fuentesbuenas, Horcajadilla, Hortizuela, Jabaguilla, La Osa y Villalbilla (en Chillarón), etc. 


\section{LOS TÉRMINOS DESPOBLADOS Y SU APROVECHAMIENTO}

Como es habitual en tantos lugares del reino castellano, los despoblados conservaban en Cuenca su término y, al no haber vecinos, el aprovechamiento del mismo quedaba a disposición de la ciudad y tierra. Lógicamente, la dehesa boyal y el ejido dejaban de tener sentido, confundiéndose con el espacio comunal, aunque no por ello se olvidaban del todo y en caso de repoblación del lugar se volvían a poner en uso ${ }^{23}$. Sin embargo, lejos de las miradas el abuso era muy fácil y no resultaba nada raro que estos espacios de uso público terminaran mezclándose con las propiedades de hacendados relevantes allí establecidos. Por eso en algún momento el concejo ciudadano se inclina por guardar la dehesa, no sólo para facilitar la eventual instalación de eventuales colonizadores sino a fin de evitar entradas ilegales ${ }^{24}$.

La ciudad de Cuenca, como todos los grandes concejos del centro de la Península, siempre rechazó las pretensiones de integración de los términos despoblados en las demarcaciones dependientes de las aldeas próximas. Es indudable que para todas ellas la aparición de uno de estos despoblados abría múltiples expectativas como posible ámbito de expansión para pastos o roturación y, por lo tanto, antes o después surgía en los pueblos más sólidos la tentación de absorberlos. En comunidades de villa y tierra más débiles se comprueba que esto no era raro, pero en el caso de Cuenca la firmeza de la ciudad constituía un obstáculo difícil de superar. Un pueblo grande, como era La Parrilla, lo intentó en fechas tempranas con respecto a Aldehuela, casi arrinconada entre el territorio parrillano y los límites exteriores de la jurisdicción conquense, pero no tuvo el menor éxito ${ }^{25}$. Otra posibilidad consistía lisa y llanamente en la ocupación, como hizo el lugar de Pozuelo en el término de Huertabellida ${ }^{26}$; mientras que una tercera opción suponía el uso de estos espacios por parte del vecindario del lugar cercano, pero sin entrar a considerar su condición jurídica. Era ésta una situación de hecho que se dio en el caso de Palomares, aprovechado por los vecinos de Cañizares durante tanto tiempo "que memoria de onbres non es en contrario", según decían ellos mismos avanzado el siglo XV. Lo hacían con conocimiento del concejo ciudadano, solo que en los años

23. AMC, leg. 6-6, 82-2, 65-2. Una orden real disponía que se diese a los eventuales repobladores tanto ejidos como dehesa boyal. En 1513 el concejo había autorizado la permanencia de la dehesa de Castillo de Albaráñez argumentando que estaba poblado por cinco vecinos. AMC, leg. 64-3.

24. Se observa tal cosa ya en fechas tardías, cuando probablemente existían ciertas expectativas de repoblación. AMC, leg. 74-1.

25. Consta que en 1431 se hacían gestiones a este respecto porque las cuentas de aquél año incluyen una partida que a ello se refiere. AMC, leg. 188-2, f. 1r-13r. En la cercana ciudad de Huete está muy bien documentado el pleito que enfrentó al lugar de Torrejoncillo con el concejo urbano y otras aldeas de su sexmo, al reclamar el primero la incorporación de cuatro despoblados existentes en sus inmediaciones, cuyos habitantes, al parecer, se habían desplazado al pueblo demandante. Al oponerse las autoridades de Huete, el asunto llegó a la Corte y se prolongó durante más de veinte años. Ver detalles en J.M. SÁNCHEZ BENITO. Ciudad, territorio y poder: Huete y sus aldeas en el siglo XV. Cuenca, 2006, pp. 137 y 156-57.

26. AGS, RGS, 1497-II, f. 127 y 137; AMC, leg. 43-2 y 3. 
noventa la institución municipal conquense comenzó a arrendar este término y entonces los de Cañizares, viéndose privados de su uso, protestaron y hubo pleito ${ }^{27}$.

Ciertamente, la ciudad nunca estuvo dispuesta a ceder su competencia en lo que se refiere a la configuración de los términos rurales ni, por lo tanto, transigió en la integración de cualquiera de ellos en los pertenecientes a las demás aldeas. No podía aceptar que las municipalidades rurales, por su propia iniciativa, terminasen introduciendo cambios en el mapa de la tierra. De este modo, solamente se aprobó la modificación de los ámbitos correspondientes a determinados despoblados con el fin de evitar riesgos de señorialización, o bien que propietarios privados los convirtiesen en términos redondos. Así se hizo en los tiempos difíciles de 1467, cuando la inestabilidad política facilitaba toda clase de amenazas a la integridad de la jurisdicción conquense, optando por transformar La Losilla en común a las aldeas vecinas, Zarzuela y Collados ${ }^{28}$. Otra modificación parecida se hizo el mismo año al fusionar - nunca definitivamente- los de Castillejo y Fresneda de la Sierra. En realidad, la debilidad de Fresneda era considerable, apenas tenía dos o tres vecinos procedentes de Poyatos y estaban mucho más vinculados a su lugar de origen, perteneciente a los estados del linaje Mendoza ${ }^{29}$. Así que era el temor por la integridad de la tierra lo que llevaba a la adopción de medidas excepcionales en un momento que también lo era.

En lo que concierne al aprovechamiento de estos espacios, de magnitud en absoluto despreciable, sabemos que en el agostadero, y a lo largo de un plazo que primero se extendía durante nueve semanas y después once ${ }^{30}$, los términos de todas las aldeas se cerraban, impidiendo el acceso a los mismos de todo ganado que no fuese local. Aunque los motivos de esta costumbre resultan evidentes, como consecuencia de la recogida de la cosecha y la escasez de pasto en pleno verano, consta que al comenzar el siglo XV se procedía al arriendo de estas hierbas de los despoblados. Era una manera de aliviar las cargas fiscales de los vecinos de la tierra, pues la mitad de este ingreso se detraía de lo que en conjunto debían pagar los pecheros, pero también beneficiaba a los caballeros que tenían heredades en estos términos e incluso las ordenanzas promulgadas en tiempos de Fernando de Antequera nos muestran que los caballeros presionaban para que se efectuasen tales arrendamientos, porque ellos llevaban la mitad del beneficio ${ }^{31}$. Así pues, aunque

27. Al respecto J.I. ORTEGA CERVIGÓN. La acción politica y la proyección señorial de la nobleza territorial en el obispado de Cuenca durante la Baja Edad Media. Tesis doctoral Universidad Complutense de Madrid, 2006, pp. 590-91.

28. AMC, leg. 198-1, f. 38r-41v y 62r-75v.

29. AMC, leg. 198-1, f. 20v-21r y 30v. Se refiere a este hecho J.I. ORTEGA CERVIGÓN. $L a$ acción politica y la proyección señorial de la nobleza territorial, pp. 709-10.

30. Un documento de 1497 -AMC, leg. 5, f. 83 y AGS, RGS 1498 II-277- especifica que el cierre de los términos tenía lugar entre las fiestas de San Pedro y San Pablo y San Cebrián, o lo que es lo mismo entre finales de junio y mediados de septiembre, es decir, once semanas. En algún testimonio más antiguo se puede encontrar el plazo de nueve semanas.

31. Las ordenanzas de Fernando de Antequera fueron publicadas por M.D. CABAÑAS. "La reforma municipal de Fernando de Antequera en Cuenca", I ${ }^{o}$ Simposio Internacional de Historia de Cuenca. Cuenca y su territorio en la Edad Media, 1982, capítulo XXVIII, p. 394. El reparto por mitades fue confirmado por la corona en 1481. AMC, leg. 201-3, f. 9r-v. Esta forma de hacer las cosas 
la costumbre es anterior al siglo XV, a partir de los años veinte se conservan varios listados de lugares cuyas yerbas se arrendaban del modo indicado, reflejándose las cantidades correspondientes a los pecheros en las cuentas que se hacían para elaborar los repartimientos anuales ${ }^{32}$. Pronto se empezó a contratar su aprovechamiento por períodos plurianuales, proliferando rápidamente esta fórmula ${ }^{33}$, y el negocio adquirió complejidad porque los beneficiarios recurrían a la práctica del subarriendo. Se hacía mediante acuerdos privados entre el arrendatario y otros ganaderos, y lógicamente no ha quedado en el archivo municipal conquense testimonio documental de los mismos. Sin embargo, no solamente conocemos su existencia sino que también sabemos que era bastante habitual, así que desde la ciudad se introdujeron condiciones para que no beneficiasen a vecinos de los muchos señoríos comarcanos, a menudo colindantes con los lugares deshabitados ${ }^{34}$. Recordemos lo que ya hemos adelantado acerca de los peligros que amenazaban la integridad del territorio encabezado por la urbe.

Al observar la lista de arrendatarios que hemos podido reconstruir utilizando las actas municipales de la ciudad, inmediatamente salta a la vista la presencia de varios notables de la misma, pertenecientes a unos trece linajes del máximo nivel dentro de la vida urbana. Hay incluso entre ellos un noble territorial tan importante como era Lope Vázquez de Acuña, interesado en los años treinta por el pasto veraniego de Arcos de la Sierra. Algunos de estos personajes aparecen con verdadera continuidad en determinados lugares, como Atalaya (donde generación tras generación figuran representantes del linaje Cañizares), Cañamarejos (Álvarez de Toledo), Perales (los Sacedón) y algún otro. En estos casos es evidente la implantación que tales individuos tenían en cada uno de estos lugares, donde sus propiedades tendrían un peso literalmente absorbente. En otras oportunidades se detecta un determinado apellido actuando en un sector geográfico en el que sabemos que tenía intereses muy relevantes. Así, Fernando de Ribera en la zona montañosa de Cabrejas, en la cual esta familia recibirá nada menos que el señorío de Villarejo de la Peñuela, situado en tierra de Huete, justamente al otro lado de los mojones que separaban Cuenca de esta ciudad. Sabemos que el mencionado Fernando de Ribera arrendó el término del lugar que precisamente se llamaba Cabrejas, así

no es privativa de Cuenca, aunque hubo localidades del centro peninsular en las que no se recurrió al arrendamiento de estas hierbas. Ver M. DIAGO. "Los términos despoblados en las comunidades de villa y tierra del Sistema Ibérico castellano", pp. 495-96.

32. Había en la tierra conquense repartimientos anuales para cobrar la martiniega y el llamado pecho de San Miguel, forero, soldadas, costas y derramas acostumbradas. Ver Y. GUERRERO NAVARRETE, J.M. SÁNCHEZ BENITO. Cuenca en la Baja Edad Media: un sistema de poder urbano. Cuenca, 1994, pp. 55-60, 209-10 y 227-36, así como el trabajo específico de A.C. SÁNCHEZ PABLOS. "La fiscalidad municipal en la tierra de Castilla en el siglo XV: el pecho de San Miguel en el territorio de Cuenca", Fiscalidad, sociedad y poder en las ciudades castellanas de la Baja Edad Media, Madrid, 2006. Relaciones de arrendamientos de las hierbas de los despoblados en AMC, leg. 185-6, f. $41 \mathrm{r}-\mathrm{v} ; 186-2$, f. $39 \mathrm{v} ; 187-3$, f. $14 \mathrm{r}-43 \mathrm{v} ; 187-5$, f. 4r-20r; 188-2, f. 1r-13r; 188-5, f. 1r-13r; 188-3, f. 1r-11r; 189-2, f. 33v-44v; 189-5, f. 21v-32v; 190-7, f. 37r-50r; 192-1, f. 43v y ss.

33. Los plazos oscilaban entre cinco y nueve años. AMC, 189-4, f. 27v; 194-2, f. 29v; 201-4, f. $15 \mathrm{v}-16 \mathrm{r}$.

34. AMC, leg. 190-7, f. 50r-v.

HID 40 (2013) 327-359 
como Valdecabrillas, muy cerca; y su mujer lo hizo en Valmelero, también en el mismo sector ${ }^{35}$.

Hemos subrayado antes trece linajes más destacados, casi todos con algún representante en el regimiento conquense durante el siglo XV. Entre ellos cabría resaltar especialmente a aquellos que se repiten en un mayor número de veces, pues tal cosa vendría a ser indicio certero de su interés por los recursos de la tierra y sus deseos por estar presentes en ella. Me refiero en particular al regidor Sancho de Jaraba, cuyas ambiciones por obtener algún señorío conocemos muy bien por otras fuentes y se deja ver en el arrendamiento de no menos de siete términos despoblados; el también regidor Juan González de Alcalá tiene una presencia aún mayor; y por detrás el regidor Martín García de Sacedón. Es cierto además que Sancho de Jaraba también había actuado como intermediario para facilitar el arrendamiento que Lope Vázquez de Acuña hiciera en Arcos de la sierra, de manera que en esta clase de negocios - como en tantos otros- la red de relaciones sociales ocupa un lugar imprescindible. Ahora bien, que el interés de ambos personajes -Acuña y Jaraba- no quedaba en el uso de los pastos sino que se refería, más en general, al control de espacios realengos lo corrobora un hecho cual es que ambos utilizaron la presión para impedir que otros se hicieran con el arrendamiento de estas hierbas. El primero de ellos, el poderoso Lope Vázquez, se oponía en 1427 al remate de Titos y Arcos de la Sierra, alegando que valían más y enviando un hombre al concejo para que en su representación hiciera patente su negativa. En 1432 no se registran ingresos en Arcos porque se impidió a los ganaderos consumirlo, y poco después aparecen como arrendatarios el propio Acuña y Sancho de Jaraba. Claro que nunca hay que descartar el interés puramente pecuario, pues el ganado de Acuña no solo recorría el sector de Arcos sino también otros puntos de la tierra, beneficiándose sin pagar de más de un despoblado. En todo caso, del segundo de los mencionados, Jaraba, se sabe que bastantes años más tarde seguía utilizando las mismas prácticas de presión e impedía sobre el terreno que el pasto se comiese ${ }^{36}$. Pero si las miras de los anteriores estaban puestas en la influencia sobre la tierra, el linaje Requena, vinculado a la mayordomía del concejo en esta misma época, tiene que ver mucho más con la intermediación y la reventa de las hierbas. De esta suerte, Fernán López de Requena sigue una conducta totalmente distinta a la que hemos visto en los personajes anteriores, pues no solamente interviene en puntos geográficos de lo más diverso, es que siempre lo hace sin la menor continuidad.

En conjunto la élite urbana actúa con mayor o menor insistencia en más de la mitad de los lugares despoblados de la tierra y su papel es ciertamente relevante. Sin embargo, no son ni mucho menos los únicos. Hay que contar también con los numerosos aldeanos que en algún momento se fijan en estos pastizales

35. Años más tarde otro miembro de la misma familia, también llamado Fernando de Ribera, y su madre, insistían al concejo conquense para que les permitiese pastar con 1500 cabezas precisamente en Cabrejas y Valmelero. AMC, leg. 205-4, f. 4v-5v.

36. AMC, Leg. 187-3, f. 14r-43v; 188-3, f. 1r-11r; 81-10. La oposición de Acuña al remate de Titos en 1427 seguramente tiene que ver con el enfrentamiento político que existía entre este personaje y el linaje Mendoza. 
y que, considerándolos a todos, se dejan notar en la mayor parte de los términos despoblados conquenses, por encima de las dos terceras partes. Lo que ocurre es que no debemos pensar únicamente en campesinos más o menos acomodados que tuvieran interés en las posibilidades que ofrecían demarcaciones próximas a su lugar de residencia. Hay individuos cuyo alcance llega a diferentes lugares de su propio sexmo -cual Juan Sánchez de Reillo, en el de Arcas; Juan Fernández del Amo, en el de la Sierra- e incluso mucho más lejos, según muestra el vecino de Valera Pascual López de Villar del Saz, arrendatario en lugares de tres sexmos distintos. No seguiremos dando nombres, aunque podríamos hacerlo, pero sí hay que dejar bien claro que ninguno de ellos aparece de manera continuada en un mismo término. Todo indica que era un negocio que vendría a sumarse a las actividades de hombres cuyas capacidades económicas les otorgaba un radio de acción que desbordaba con mucho los límites de su pueblo.

En fin, aldeanos de cierta relevancia, por un lado, y miembros de la élite urbana, por otro; tales son los principales protagonistas de estos contratos. En el resto de los casos se trata de ciudadanos que en su mayoría no se repiten y entre los cuales hay propietarios de cierta importancia -García Álvarez de Salas o Rodrigo de Atienza-, bien implantados en aquellos ámbitos de la tierra en los cuales efectúan ciertos arrendamientos. Claro que tampoco faltan los que buscan negociar con este recurso. Tal sería el caso de los escribanos Alvar González de Huerta y Alfonso López de Santorcaz, ambos muy interesados en los asuntos de la tierra y dispuestos a intervenir en funciones de intermediación. Son siempre personas que conocen bien el ámbito jurisdiccional conquense y cuentan con amplias relaciones en el mismo ${ }^{37}$.

Ahora bien, desde los años cincuenta las cuentas que podemos utilizar para nuestras averiguaciones dejan de especificar las cantidades de dinero correspondientes a cada uno de los despoblados e indican que estos pastos se arrendaban en conjunto. Al principio aparece ocupándose de ello algún aldeano ya conocido -el vecino de Arcas Juan Sánchez Reillo-, pero al paso del tiempo esta fuente de ingresos se vincula al mayordomo de la ciudad, que salvo los primeros años es siempre el arrendatario, de forma que éste se ocupaba de realizar labores de receptoría en la tierra, especialmente en lo que afecta a la martiniega. Fácil es imaginar que tales usos daban lugar a confusiones. Pero es que además, al tiempo que esto ocurría, se observa que la rentabilidad obtenida de estas pasturas veraniegas tiende a decrecer hasta que pronto se estabilizó en los 2000 mrs., la mitad de los cuales se destinaba a un yantar para los sexmeros. En fin, es oportuno resaltar que dicha cantidad es menor que la suma de los ingresos procedentes de cada uno de los despoblados que aparecen en las contabilidades de los años anteriores ${ }^{38}$.

37. Se refiere a los arrendatarios de las hierbas de los despoblados J.A. JARA FUENTE. Concejo, poder y élites. La clase dominante en Cuenca en el siglo XV. Madrid, 2000, p. 327 y lista parcial en pp. 442-46.

38. AMC, leg. 194-4, f. 1r-2v; 195-1, f. 78v; 195-2, f. 30v; 195-3, f. 15r-27v; 196-1, f. 16v; 198-1, f. $82 \mathrm{r}-83 \mathrm{v} ; 198-3$, f. $76 r-90 r ; 200-2$, f. 13r; 200-3, f. 19v; 201-2, f. 133r; 201-4, f. 15r-v; 203-1, f. 55v; 204-1, f. $63 \mathrm{v} ; 205-1$, f. 37r-v. 
Poco después se detecta que el concejo ciudadano empieza a arrendar algunos términos despoblados no solo en lo referente a las hierbas del agostadero sino para el aprovechamiento permanente de sus recursos. Al principio no parece que se autorizase otra cosa que el pasto y la leña, excluyendo expresamente la posibilidad de hacer rozas para sembrar, pero pronto los contratos se hacían de manera mucho más general, para explotar la labor, hierba y corta. Eso sí, con arreglo a la tradición jurídica local nunca se aceptó la exportación de madera fuera de la tierra y por eso ocasionalmente se introduce la condición de notificar a la ciudad la venta de pinos. Estos contratos eran siempre plurianuales, por plazo que si alguna vez es muy breve llega a menudo hasta los nueve años.

Se actuó de este modo en Arguisuelas, arrendada en las mencionadas condiciones a los vecinos de Monteagudo, que era señorío episcopal. El lugar estaba vacío y el concejo conquense obtenía buena renta de unos aldeanos que en el último tercio del siglo desarrollaban una dinámica claramente expansiva y precisaban terrenos de cultivo. Justamente por esto la renta tiende con fuerza al alza, al mismo tiempo que arrecian las protestas del común de la tierra. La conjunción de ambos factores llevó en el caso de Arguisuelas a la inestabilidad, de manera que desde 1479 se sucedieron los contratos con rapidez a favor de varios notables de la ciudad, a la vez que las localidades próximas, que en este caso estaban todas situadas fuera de la demarcación conquense, intervienen también intentando obtener el arrendamiento. Más tarde, en los años noventa, varias personas se avecindaron allí y nuevamente el común de la tierra dio muestras de su descontento denunciando que los citados colonizadores no habían hecho correctamente su avecindamiento $y$, en consecuencia, estaban ilegalmente en Arguisuelas ${ }^{39}$. Es lo cierto que este despoblado es un poco peculiar al estar rodeado a ambos lados por jurisdicciones extrañas, concretamente los señoríos del obispo y la tierra de Moya. Sin embargo, las quejas de la tierra son continuas y la argumentación que les sirve de fundamento se repetirá muchas veces. Dicha argumentación se basa en lo siguiente: a) los pecheros de la tierra salían claramente perjudicados con esta clase de arriendos, b) el procedimiento administrativo para llevarlos a cabo no era claro, c) el beneficio de las hierbas del agostadero perteneciente a la tierra desaparecía, d) dichos arriendos convertían de facto en propios los términos afectados $\left.{ }^{40}, \mathrm{e}\right)$ muchas veces los beneficiarios eran foráneos en perjuicio de la integridad del realengo, f) y, además, todo esto favorecía a la élite en el poder ${ }^{41}$. En realidad, lo que el común de la

39. AMC, leg. 201-2, f. 73-79 y 106v-107r; 201-4, f. 44v-45v; 203-2, f. 274v-75r y 280; 204-2, f. $17 \mathrm{r}-19 \mathrm{v} ; 5-40 ; 75-1 ; 44-3$; A.G.S. R.G.S., IX-1485, f. 166.

40. Procede recordar en este punto que en la cercana Huete se constituyeron dehesas de propios en lo que fueron despoblados, alguna vez mediante procedimientos muy poco claros. Ver mi libro Ciudad, territorio y poder, pp. 157-59.

41. Además de la documentación de Arguisuelas, AMCu, leg. 64-2 y 65-2, así como AGS, RGS 1492-XI, f. 231, en 1492 se denunciaba que algunos regidores para complacer a señores territoriales les arrendaban términos en los que sus vasallos pudiesen roturar, $\mathrm{AMCu}$, leg. 5-53. En el mismo corredor sureste del sexmo de Arcas y justamente en los límites meridionales de Arguisuelas, se encontraba otro lugar deshabitado llamado Yémeda, muy semejante al anterior y del que también tenemos información sobre su arrendamiento desde los años ochenta. La situación es similar, solo que había además un 
tierra quería de verdad es que los pueblos inmediatos a los despoblados no tuviesen limitaciones para aprovecharse de ellos, utilizándolos para superar la estrechez de sus propios términos y canalizar su capacidad de expansión.

En fin, lo que queda claro es que las citadas contrataciones generaban un ingreso para la ciudad en perjuicio de la tierra. Cabe pensar que el arrendamiento de las hierbas de los despoblados había seguido una deriva que conducía a confusiones y probablemente el concejo ciudadano fue desarrollando un proceso de apropiación, al menos parcial, de los derechos que sobre estos dineros correspondían a los pecheros ${ }^{42}$. Era una forma de escamotear el único ingreso que el común tenía y es natural que las protestas lejos de diluirse se convirtieran en tema relevante para los pecheros de la tierra. Si la poca fuerza del común ${ }^{43}$ abrió el camino al concejo y a la élite conquense para beneficiarse - por esta y por otras vías- de los términos despoblados, los vecinos rurales y sus representantes no podían ceder en ello. Estaba en juego el espacio de unos y otros -común/concejo ciudadano y su élite- en las relaciones de poder que tenían lugar en el extenso territorio cuya cabeza estaba en la ciudad. De este modo, a fines del siglo XV las denuncias del común terminaron centrándose en el receptor de la ciudad, pues se ocupaba de todos los dineros relativos a la tierra, y especialmente los derivados de los despoblados, debatiéndose sobre la imposibilidad de ejercer algún control sobre su actividad por parte de los pecheros. Casi por pura lógica los de la tierra terminaron reclamando un receptor propio. A tal fin, recurrieron a la corona y hubo pleito con sucesivas apelaciones, pues en principio las resoluciones judiciales les favorecieron ${ }^{44}$. En definitiva, debemos entender que los despoblados constituyeron una de las claves sobre las cuales se articula la organización de los pecheros de la tierra.

\section{HACENDADOS Y USURPADORES}

Al iniciarse el siglo XV la magnitud de la propiedad fundiaria en manos de ciudadanos tenía un alcance realmente muy grande. Durante decenios tanto los caballeros de la urbe como otros vecinos mucho más modestos habían realizado multitud de compras y el resultado es que todo individuo relevante poseía bienes de esta clase, al mismo tiempo que muchos artesanos y gentes del común ciuda-

problema añadido: los vecinos limítrofes del señorío episcopal disputaban el paraje de Cañada de la Madera y los labradores de Cardenete, tierra de Moya, que tenían siembras en virtud de los acuerdos establecidos con Cuenca se enfrentaban a ellos. En algún momento se llegó a la violencia entre unos y otros. AMC, leg. 203-2, f. 236v-38r; 204-2, f. 23v; 219-1, f. 124r-v; 42-3; 42-4. Sobre el arrendamiento de manera similar del término de Villaverde, AMC, leg. 203-1, f. 2r-8r; 204-2, f. 39v-40r; 44-2; 44-3; 198-2.

42. AMC, leg. 5-83 y AGS, RGS 1497-II, f. 277.

43. En contraste con el común de la tierra de Molina, mucho más sólido y organizado.

44. AMC, leg. 5-78 y AGS, RGS 1495-IX, f. 201; 68-4 y 65-3. Paralelamente se disputaba sobre la toma de cuentas. 
dano habían llegado a adquirir alguna parcela o las tenían por herencia ${ }^{45}$. Para el grupo dominante la disponibilidad de tierras no sólo aportaba renta sino también prestigio e influencia en la tierra, así que contaban frecuentemente con heredades considerables que aparecen por todo el territorio, acaso con la excepción relativa del sexmo de la Sierra, más lejano y peor documentado, donde la implantación de estos propietarios relevantes parece menor. Además, dichos personajes nunca dejaron de adquirir nuevos fundos, de tal modo que la presencia que en conjunto tenían en el espacio cultivado era enorme y crecía sin cesar. Ahora bien, en este momento lo que nos interesa no es el análisis general de la propiedad sino su relación con los términos despoblados que constituyen el objetivo de este artículo.

Una de las mejores pistas para corroborar la presencia de la gran propiedad en un determinado lugar es la existencia de avenimientos fiscales, es decir acuerdos mediante los cuales un hacendado pactaba con la ciudad la contribución de sus renteros durante un determinado número de años. Conviene recordar que los vecinos de la tierra pagaban regularmente la martiniega y el pecho de San Miguel, y para ello, así como para atender los impuestos directos de la corona, atribuían a cada uno, según sus posibilidades económicas, cierto número de centenas hasta un máximo de ocho, que era la unidad completa o postería, repartiéndose luego las cantidades a pagar con arreglo a las centenas de cada uno. Pues bien, los mencionados avenimientos podían incluir la martiniega, el pecho de San Miguel o también las cargas del fisco regio, y lo que se hacía en ellos era establecer una cantidad fija sin tener en cuenta el sistema de posterías y centenas. A veces el concejo ponía como condición que los habitantes de la tierra no pudiesen ir a morar a los lugares afectados, pues ya pagaban de manera ordinaria y el avenimiento vendría a suponer una rebaja en perjuicio de los demás pecheros. Sin embargo, se sabe que en Aldehuela, por ejemplo, se beneficiaban del avenimiento vigente en 1431 nueve vecinos de la tierra de Cuenca y siete de fuera, sin contar el mayordomo que allí tenía el propietario, pues los mayordomos de los caballeros eran excusados que no pagaban la martiniega y tampoco el pecho de San Miguel. Estos convenios se aplicaron en diferentes ocasiones, al menos desde principios del siglo XV, y como es natural facilitaron la explotación de muchos despoblados por parte de los hacendados poseedores de las tierras de cultivo que en ellos había. Algunos de estos

45. He estudiado este proceso en mi libro Las tierras de Cuenca y Huete en el siglo XIV, pp. 132-34. Independientemente de las citadas compras no hay que perder de vista la decisión tomada por el concejo conquense hacia la mitad del siglo XIII, "quando nos el concejo fizimos la partición de la nuestra sierra", otorgando a ciertos miembros de la caballería villana quiñones para que los labrasen y de esta manera humanizar las superficies vacías. Cada uno de dichos quiñones incluía derechos de adehesamiento. De esta manera individuos situados en la cúspide de la sociedad adquirieron sólidas posiciones en la sierra. Ibídem., pp. 19-20 y 60-61. Hay realidades parecidas en otras ciudades, así, por ejemplo, F.J. LORENZO PINAR. "Términos redondos y despoblamiento en Ávila al inicio de la Edad Moderna. Aproximación histórica”, Studia Zamorensia $2^{a}$ etapa, VI (2002), p. 260, se refiere a los adehesamientos aprobados por Alfonso X en tierra de Ávila. Sobre la fuerte presencia de los herederos ciudadanos en un pueblo de cierta importancia como es Fuentes puede verse mi artículo "Una aldea realenga y su concejo", pp. 296-98. 
lugares permanecieron avenidos durante decenios, como es el caso de Atalaya o La Cierva ${ }^{46}$.

Si bien los referidos avenimientos ofrecen indudablemente un indicio muy relevante para nuestro propósito, reuniendo datos de diversa índole encontramos un buen número de despoblados en los cuales la repercusión de uno de estos grandes herederos es seguramente determinante. Podríamos citar los casos siguientes, sin pretender en absoluto que la lista que ofrecemos sea completa, ni siquiera aproximada:

- Sexmo de ALTAREJOS: Aldehuela, Cañada del Manzano, Mezquitas, Villarejo de Periesteban, Villaverde.

- Sexmo de ARCAS: Atalaya, Ballesteros, La Cierva, La Melgosa, Olmedilla, Yémeda.

- Sexmo del CAMPO: Arcos de la Sierra, Embid, La Losilla, Titos, Verdelpino.

- Sexmo de CHILlARÓN: Albaladejo, Cabrejas, Cañamarejos, Colliguilla, Fuentesclaras, Fuenteferruz, Hortizuela, La Osilla, Las Tejas, Nohales, Tondillos, Valdecabrillas, Valmelero.

- Sexmo de LA SIERRA: Solana y Murillejo.

- Sexmo de TORRALBA: Fuentesbuenas, Olmedilla Eliz, Perales, Valdecañas.

Con todo, hay que decir que nuestras limitaciones son grandes para el estudio del problema que hemos planteado, no sabemos la trayectoria que en lo referente a la propiedad sigue cada término, y cuando tenemos más detalles es debido a pleitos relacionados con ocupaciones y abusos. De modo que para conocer los detalles hay que esperar a fechas tardías, ya comenzado el siglo XVI, pues solo entonces encontramos los autos más o menos completos de varios de ellos ${ }^{47}$. En todo caso, a la vista de la relación precedente, lo primero que hay que destacar es que en los sexmos de Arcas, Altarejos y Chillarón alrededor de la mitad de los despoblados conocidos presentan en sus términos, con toda seguridad, grandes propiedades, mientras que en los del Campo y Torralba la proporción sube por encima del $60 \%$. Como quiera que en muchas oportunidades no disponemos de datos hay que entender que serán bastantes las propiedades importantes que en otros lugares se nos escapan por completo, y no faltan las sospechas al respecto en muchos sitios. Por consiguiente, concluiremos que despoblados y heredamientos de esta índole son fenómenos bastante paralelos, podríamos decir que van en gran medida de

46. Entre dichos hacendados había miembros de familias de peso en la élite conquense, cual Alarcón, Guadalajara y Cañizares; o bien ciudadanos cuantiosos de menor calibre. Los lugares afectados son: Aldehuela, Atalaya, Cañada del Manzano, Castillejo Albaráñez, Fuenteferruz, Fuentesbuenas, Hortizuela, La Cierva, Las Tejas (del sexmo de Chillarón), Murillejo, Solana, Villarejo de Periesteban, Yémeda. AMC, leg. 186-5, f. 8r-80v; 187-5, f. 51r; 188-2, f. 1r-13r; 188-5 (2ºuaderno), f. 1r-13r; 189-1 ( $2^{\circ}$ cuaderno), f. 27v-28v; 190-7, f. 37r-50r; 192-1, f. 43v; 194-2, f. 29v y 65v; 194-4, f. 28r-29v, $52 \mathrm{r}$ y $55 \mathrm{v} ; 195-3$, f. $15 \mathrm{r}-27 \mathrm{v}$.

47. Con buen criterio observa M. DIAGO. "Los términos despoblados en las comunidades de villa y tierra del Sistema Ibérico", p. 473, que con frecuencia nuestra información sobre los despoblados surge de manera paralela a la usurpación de los términos por miembros de la oligarquía urbana. 
la mano. De todos modos, cabe introducir algún matiz, pues se nota claramente que la presencia de estos fundos aumenta hasta casi hacerse absorbente en las proximidades de la ciudad. En cambio, en el sexmo de la Sierra la mayor distancia con respecto a aquella disminuye la influencia que irradia desde el núcleo central. Probablemente la gran propiedad de la clase dominante de Cuenca no fue aquí factor tan decisivo.

En cuanto a los dueños de tales heredamientos, encontramos linajes que llegaron a situarse en el regimiento -Álvarez de Toledo, Alarcón, Cañizares, Guadalajara, Jaraba, Sacedón- e incluso a los poderosos Mendoza, pero también personajes de menor relumbrón, como Martín de Soria, que, con todo, pretendía constituir término redondo en La Losilla, del que hablaremos después. Aunque es grande el dinamismo que suelen seguir las propiedades rurales de muchos ciudadanos, los linajes de mayor relieve fueron constituyendo sólidas heredades en los lugares de la tierra conquense, muchas de las cuales estaban ya perfectamente cristalizadas en el siglo XIV. Solo que cuando esto ocurría en pueblos muy pequeños, entonces el peso que allí tenía el propietario era prácticamente ilimitado. Esto explica que el número de lugares habitados casi en exclusiva por renteros no era despreciable, tal como ha quedado indicado con anterioridad.

Puede servir como ejemplo el caso de Villaverde, situado en los confines de la jurisdicción urbana y donde el concejo de la ciudad reconocía expresamente en 1419 que Juan Fernández de Valera poseía todo el terreno cultivable. Por lo tanto, se trataba de una gran propiedad cuyo inicio por fuerza tendremos que localizar antes de 1400. Solo que un año antes, en 1418, la Catedral, que también tenía parte en aquella localidad, pleiteaba contra Valera por los derechos de herbaje. La cuestión parece bastante clara, Juan Fernández de Valera, perteneciente a una familia importante en la ciudad, pretendía formar allí un término redondo sobre la base de su condición como propietario mayoritario. Para ello dejaba al margen a la Iglesia conquense -compradora de una heredad en 1339 y que en 1353 obtenía sentencia del alcalde entregador de la Mesta a favor de un adehesamiento en el lugar-y pretendía ejercer el control de montes y baldíos. La ciudad reaccionó reconociendo su posesión de las tierras de uso agrario pero manifestando expresamente que el término como tal no era privado y estaba sujeto a las servidumbres comunitarias correspondientes a su pertenencia a la jurisdicción conquense. Con posterioridad, el heredamiento pasó a Diego Hurtado de Mendoza y en la generación siguiente Juan Hurtado e Íñigo López lo donaron a la clerecía catedralicia. De esta suerte, desde los años sesenta y durante décadas los eclesiásticos obtuvieron los arrendamientos del pasto, incluyendo el derecho a cortar leña, mediante contratos plurianuales que se iban sucediendo a lo largo del tiempo. En los últimos años del siglo trajeron un mayor número de renteros y eso unido a su presencia exclusiva en el término durante largo tiempo condujo al conflicto. El concejo, efectivamente, comenzó a denunciar que los baldíos eran usurpados haciendo roturaciones y aprovechando privadamente sus recursos. La situación era tan confusa que mientras la ciudad alegaba que la heredad privada allí existente no pasaba de las tres yugadas, los clérigos decían que desde siempre habían poseído todo el terreno de sembradura 
y para ello tenían dehesa antigua. Los renteros moradores de Villaverde también aportaban su propia argumentación señalando que eran diez vecinos y, por lo tanto, formaban pueblo con derecho al aprovechamiento comunal. En fin, uno de tantos pleitos que por parecidas razones surgieron alrededor de 1500, cuando, al compás de la coyuntura alcista, la presión que campesinos y propietarios ejercían sobre el territorio obligaba a limitar sus usos y a vigilar todo lo posible los comunes ${ }^{48}$.

En todo caso, estos datos, que no son nada infrecuentes, ponen de manifiesto con toda claridad que el abuso y la violación de la legalidad que servía de base a las comunidades de villa y tierra están íntimamente unidos a la problemática de los despoblados. Se puede afirmar sin reservas que el despliegue de los mismos se produce de manera paralela al desarrollo de múltiples usurpaciones de diversa indole, encaminadas a extraer tierra y recursos fuera de la unidad de aprovechamientos comunales que significaba el alfoz de una ciudad como Cuenca.

En realidad, el problema se resume con facilidad. Los propietarios que tenían la mayoría y, a veces, todas las heredades existentes en un determinado lugar; es decir, una posición dominante en el mismo, aprovechando la escasa presencia humana intentaban monopolizar los baldíos allí existentes, impidiendo el acceso a los vecinos de la ciudad y tierra. Lo hemos visto en el caso de Villaverde y se comprueba que si no había quien pudiera oponerse eficazmente en el mismo lugar, tales propietarios no encontraban obstáculos para actuar con completa libertad lejos de miradas ajenas durante años. De esta manera, explotaban los recursos sin atenerse a las costumbres que limitaban el uso de los comunales, aunque sus aspiraciones no quedaban aquí sino que, en último término, pretendían cerrar el término, y esto, en su caso, podía servir como antesala para una ulterior señorialización ${ }^{49}$. Los casos son muchos -aun cuando se nos escapan bastantes-, así que se trata de un fenómeno típico. En 1467 el concejo ciudadano tuvo que intervenir en La Losilla por denuncia de vecinos de Collados y Zarzuela, a los que Martín de Soria impedía utilizar los comunales, porque precisamente quería formar lo que hemos dicho; esto es, un término redondo. El mencionado Martín de Soria no tenía demasiado peso en el sistema político y por eso no se encontraron aquí excesivas dificultades a la hora de impedir tales pretensiones, de forma que el concejo buscó remedio haciendo el término común a los dos pueblos indicados ${ }^{50}$. Algo parecido ocurrió en Morelejo, sexmo de la sierra. Allí el concejo conquense había

48. AMC, Leg. 185-4, f. 21r; 187-2, f. 26r-27v; 198-2, f. 7r; 1504; 44-2; 44-3; 203-1, f. 2r-8r; 143-1. También ACC, I, caja 18, n 22; caja 20, n 25 y Actas Capitulares del año 1418, F.A. CHACÓN GÓMEZ-MONEDERO, M.T. CARRASCO, M. SALAMANCA. Libros de actas capitulares de la Catedral de Cuenca, II (1418-22). Cuenca, 2008, n 72 y 137. La noticia del traspaso realizado por los Mendoza a la Catedral en J.I. ORTEGA CERVIGÓN. La acción política y la proyección señorial de la nobleza territorial, p. 674. Alude al caso M. DIAGO. "Los términos despoblados en las comunidades de villa y tierra del Sistema Ibérico", pp. 498-99.

49. Es oportuno recordar en este punto el artículo de J.M. MONSALVO. "Las dos escalas de la señorialización nobiliaria al sur del Duero: concejos de villa y tierra frente a señorialización 'menor' (Estudio a partir de casos del sector occidental: señoríos abulenses y salmantinos”, Revista d'Historia Medieval 8 (1997).

50. AMC, leg. 198-1, f. 38r-41v y también una referencia en las cuentas del repartimiento de aquel año, f. $62 \mathrm{r}-75 \mathrm{v}$. 
dado en 1402 especial licencia al monasterio de Ovila para que los hombres que los monjes tenían en las inmediaciones pudiesen entrar para pacer y cortar leña. En dicha concesión se reconocía expresamente que Morelejo era un despoblado de la tierra de Cuenca, pero con el paso de los decenios los monjes dieron por hecho que el término citado les pertenecía, procuraron arrendarlo para pasto y hasta consiguieron sentencias favorables de la jurisdicción más próxima a ellos, que era la eclesiástica. El uso ininterrumpido de los recursos del monte durante mucho tiempo, junto con la distancia que separaba Morelejo de la ciudad, dieron lugar a todo ello ${ }^{51}$. En fin, una ordenanza municipal de 1495 señalaba en su exposición de motivos que los renteros que trabajaban las tierras de los herederos gozaban sin traba de los pastos existentes en estos términos y a renglón seguido los señores los reclamaban en su integridad ${ }^{52}$.

Siempre el punto de partida es la existencia de una heredad situada en el término afectado, cuyo tamaño no tenía por qué ser demasiado grande debido a lo quebrado del territorio y la dificultad de encontrar tierra cultivable en extensiones importantes. A continuación, lo primordial era controlar todo el espacio, extrayéndolo de los usos comunales y entendiendo el monte como mero anexo de la heredad. Dicha pretensión se concretaba en lo siguiente:

a. El heredero se reservaba el uso de todos los recursos montaraces y especialmente los pastos, la corta de leña, el carboneo y la recogida de bellota. Naturalmente, esto tenía como consecuencia unos beneficios que iban más allá de la mera complementariedad de la economía de los renteros, pues la bellota se podía vender a otros por parte del propietario, así como también la leña y hasta se llegó a la realización de acuerdos con carboneros cobrándoles por facilitar su labor. En Hortizuela se percibieron por este concepto más de $200 \mathrm{mrs}$. por destral ${ }^{53}$. Es del todo evidente que estas cosas suponían violación flagrante de la legislación concejil.

51. AMC, leg. 5-81; AGS, RGS 1496-VII, f. 209 y 203.

52. AMC, leg. 44-3. A fin de comparar, recordemos que en la cercana villa de Molina solamente el regidor Juan de Aguilera ocupó cuatro despoblados. M.E. CORTÉS RUIZ. Articulación jurisdiccional y estructura socioeconómica de la comarca de Molina de Aragón a lo largo de la Baja Edad Media. Tesis doctoral Universidad Complutense de Madrid, 2000, pp. 407 y 1223-26, también 821-23. Con la misma intencionalidad comparativa recordemos también que M. DIAGO. "Los términos despoblados en las comunidades de villa y tierra del Sistema Ibérico", p. 474, refiriéndose a Soria afirma que desde la época de Juan II tuvo allí lugar un proceso de usurpación de términos, casi siempre despoblados. Sobre Molina, pp. 480 y ss. Al parecer, más de 50 despoblados se convirtieron en términos redondos en tierra de Ávila desde fines del siglo XV, según F.J. LORENZO PINAR. "Términos redondos y despoblamiento en Ávila", p. 257.

53. El aprovechamiento de los montes incluidos en estos términos no se limitaba únicamente a los pastos. Los recursos susceptibles de ser utilizados en régimen comunal eran muchos y el acceso a los mismos estaba mediatizado por las ordenanzas de la ciudad-cada vez más restrictivas en lo que se refiere a la libre explotación de la riqueza montaraz-, las de los concejos rurales y numerosas costumbres que se fueron desarrollando a lo largo del tiempo para que el acceso a dicha riqueza se hiciese de manera ordenada. Naturalmente, eran muy distintas las posibilidades que tenían los hacendados de la ciudad y los vecinos de la tierra para acceder a todo esto. Algunas referencias a dichos aprovechamientos en el caso concreto del despoblado de Hortizuela -aunque el artículo no se centra en esta problemática- en J.A. JARA FUENTE. “'Que memoria de onbre non es en contrario': usurpación 
b. A través de los renteros se realizaban rozas y después los señores llevaban renta por las nuevas tierras de cultivo. En numerosas ocasiones los historiadores han señalado que el siglo XV se perfila como una etapa de crecimiento demográfico y agrario en cuyo transcurso las roturaciones de baldíos aparecen al modo de una constante. En el ámbito de Cuenca, dada la naturaleza quebrada del territorio y el completo predominio del monte, se evidencia que en muchos términos despoblados, aunque hubiese herederos importantes, la superficie de cultivo era a principios del siglo XV muy pequeña, aprovechando únicamente algunos puntos más favorables junto a los cursos de agua. Después, el proceso roturador acaecido a lo largo de la centuria dio lugar a ensanches proporcionalmente considerables. A principios del siglo XVI un pleito sobre La Osilla indica que los renteros de la familia Resa habían desbrozado los baldíos durante 35 años hasta en un tercio, se supone que del término. En otro pleito de la misma época -ahora sobre Arcos de la Sierra- los testigos afirman que la heredad era reducida y la mayor parte del término era monte, aunque hay quien afirma que cuarenta años antes -inicios de los años sesenta- el lugar estaba totalmente despoblado y era todo silvestre. Curiosamente la proporción roturada es la misma que se menciona en el caso anterior. Por las mismas fechas se hizo apeo en Verdelpino de los rompimientos realizados por iniciativa de los herederos. De este modo se estableció que afectaban a siete puntos distintos, sumando en conjunto nada menos que trescientos almudes $^{54}$. Tiempo antes, una ordenanza de 1475 se refería a las rozas que hacían los renteros dedicados a las explotaciones de los herederos urbanos y les negaba toda posibilidad de apropiarse de las tierras que ganasen ${ }^{55}$.

c. Si hacía falta se utilizaba la presión y la violencia para disuadir al campesinado de cualquier conducta contraria a los intereses del señor, y hasta los caballeros de la sierra, si intervenían, podían encontrar resistencia armada.

Ahora bien, si la distancia podía favorecer estas cosas $-\mathrm{y}$ en su caso propiciar que a señores comarcanos se les ocurriese absorber en sus estados el despoblado próximo $^{56}$-, la cercanía a la ciudad de muchos de los términos en los que se registran usurpaciones indica una muy fuerte incidencia de grandes propietarios que aprovechando la abundancia de lugares montuosos en aquel entorno extienden su proyección con la facilidad que daba la poca distancia a la urbe. El problema principal era la presencia en un lugar pequeño de fuertes propietarios -fuesen quienes

de tierras y manipulación del pasado en la Castilla urbana del siglo XV", Studia Historica. Historia Medieval 20-21 (2002-03).

54. El pleito de Arcos de la Sierra, año 1503, en AMC, leg. 119-1; el de La Osilla, del mismo año, leg. 43-4; Verdelpino, en el siguiente, leg. 39-3. Dejando a un lado los despoblados, en la localidad de Fuentes se demuestra que el alcance de las roturaciones no fue pequeño. Sobre esto último ver mi artículo ya citado "Una aldea realenga y su concejo en tiempos de los Reyes Católicos", pp. 292-93.

55. AMC, leg. 1102-4 y 125-12.

56. Es el caso de Mezquitas y Yémeda. Más adelante hablaremos de la primera, en cuanto a la segunda, la iniciativa corresponde al señor de Víllora y las referencias documentales son las siguientes: AMC, leg. 64-1 y AGS, RGS 1494-XI, f. 302. 
fuesen- durante muchos años, así como la imposibilidad de controlar desde el concejo un territorio extenso y muy áspero. A partir de aquí todo dependía de la relación de fuerzas y en el caso de los despoblados - donde no había comunidad aldeana ni concejo- no existían contrapesos eficaces. Pero en cambio no se puede afirmar, más allá de algún suceso concreto, que los señores vaciasen de gente las aldeas cuyos términos pretendían controlar. Dichas aldeas eran siempre sumamente débiles y se situaban en el nivel inferior de la red de poblamiento. Tal era el marco en el que los señores actuaban una vez que obtenían tierras en ellas. Lo que ambicionaban era el territorio y la totalidad de los derechos sobre el mismo, no que éste estuviera vacío ${ }^{57}$.

Luego, las acciones de recuperación emprendidas por el concejo conquense, aunque favorecidas por la coyuntura posterior a las Cortes de Toledo de 1480, no podían ser fáciles ni mucho menos rápidas. Antes de esa fecha fue imposible reaccionar contra los abusos de manera realmente efectiva. Después, se desarrollaron numerosos pleitos durante el reinado de los Reyes Católicos, gracias especialmente a la intervención de los jueces de términos. Cabe recordar los realizados en estas fechas en relación con Arcos de la Sierra, Mezquitas, Hortizuela, La Osilla y Verdelpino, enfrentando a la ciudad contra miembros de la nobleza territorial -en el caso de Mezquitas y sobre todo Arcos de la sierra-, o bien contra distinguidos caballeros locales ${ }^{58}$.

57. Coincido completamente en este punto con M. DIAGO. "Los términos despoblados en las comunidades de villa y tierra del Sistema Ibérico", p. 474. En su artículo "Martín Sancho", pp. 485 y 495-96, J. CLEMENTE RAMOS observa la utilización de la violencia señorial para conseguir el abandono definitivo de un lugar y su conversión en dehesa susceptible de arrendamiento a ganaderos. Indica este autor que dicha violencia se presenta en fases avanzadas del proceso de desolación de un núcleo. Volviendo al ámbito conquense, J.A. JARA. "Facing the depredations and fighting the predators. Urban Castile and the defense of municipal jurisdiction in the Late Middle Ages", Imago Temporis. Medium Aevum I (2007), pp. 169-70, plantea las siguientes fases: 1/ Tomar el control de los medios de producción, adquiriendo propiedades en el término afectado, sin necesidad de obtenerlas todas. Si un heredero quedaba como el único propietario con plena capacidad de acción podía forzar la despoblación del lugar. 2/ Cierre del término a los usos colectivos, lo que equivale a formar un término redondo. 3/ Transformación si era posible del término redondo en un señorío.

58. En Mezquitas se enfrentaba la ciudad contra el señor de Valverde, del linaje Alarcón: AMC, leg. 74-8, 16-35, 67-3 y 4. En Arcos de la Sierra contra Mencía de Mendoza: leg. 108-1, 119-1 y 3. Hortizuela: 11-17, 56-1 y 110-10. La Osilla: 43-4. Verdelpino: 39-3, 63-11 y 12, 64-2. Por las mismas fechas había situaciones parecidas en Ballesteros, Olmedilla de Arcas y seguramente en otros. Con anterioridad he tratado sobre estos pleitos en mi artículo "Territorio y conflicto en el ámbito jurisdiccional de Cuenca (Época de los Reyes Católicos)", Espacio, Tiempo y Forma 9 (1996), pp. 112-15. El caso de Hortizuela ha sido estudiado con detenimiento por J.A. JARA FUENTE en el artículo ya citado "Que memoria de onbre non es en contrario': usurpación de tierras y manipulación del pasado". Pone de manifiesto la judicialización de los conflictos en esta época y analiza la argumentación de las partes. Más de pasada lo menciona también J.I. ORTEGA CERVIGÓN. La acción política y la proyección señorial de la nobleza, pp. 721-22. A través del ejemplo de Mezquitas muestra este autor la imposibilidad de ejecutar realmente las sentencias judiciales que favorecían al concejo urbano. En la segunda mitad del siglo XVI Mezquitas terminó siendo señorío de los Alarcón, pp. 573-74 y 636-37, y ya antes reservaban éstos para sus vasallos el aprovechamiento del agostadero, Archivo Histórico Provincial de Cuenca, Protocolos, 2263-2 (es el nombramiento de procurador por parte del concejo de Valera de Yuso en 1514 para pleitear por este motivo contra Jorge Ruiz de Alarcón). Ver sobre el ámbito toledano, J.-P. MOLENAT. "Une mutation du paisaje rural: villages désertés en Nouvelle Cas- 


\section{INTENTOS DE REPOBLACIÓN}

A mediados del siglo XV el concejo de Cuenca contemplaba la posibilidad de ofrecer exenciones fiscales a los pecheros foráneos que estuviesen dispuestos a habitar despoblados. Tal cosa se hacía en 1440, en el caso concreto de Arguisuelas, mediante "iguala" realizada a título individual con dos vecinos llegados del señorío vecino de Monteagudo ${ }^{59}$. De manera parecida, en 1468 se aprobó exención fiscal durante seis años a los que estuviesen dispuestos a poblar Los Oteros ${ }^{60}$. Todo indica que se trata de decisiones concretas destinadas a revitalizar lugares muy específicos atrayendo gentes de fuera de la jurisdicción. En este sentido no es casualidad que estos dos lugares estén situados en el mismo ámbito -el oriente del sexmo de Arcas, en los confines de la tierra conquense- y tengan características parecidas. Es indudable que existe voluntad política por parte del concejo buscando una cierta consolidación de estos lugares en particular.

Con anterioridad hemos hablado acerca de los "avenimientos" fiscales que se establecieron entre el concejo y ciertos propietarios para facilitarles la explotación de los heredamientos que poseían en despoblados. La utilización de este mecanismo con fines de repoblación de lugares yermos, pactando las condiciones impositivas de los renteros que un señor pretendía traer a sus tierras, se pone en evidencia en 1459. Entonces Mosén Alfonso de Alarcón se dirigía al concejo con esta intención, pues teniendo el término redondo de Fuentesbuenas, deseaba poblarlo a fin de obtener rendimiento de la heredad. Desde tiempo antes se habían hecho gestiones al respecto porque había al parecer hombres del señorío de La Ventosa que estaban dispuestos a arrendar las tierras. Así que los regidores lo aceptaron, se encargó el asunto a uno de ellos, Pedro Álvarez de Toledo, y finalmente se dispuso que el referido propietario pagase durante nueve años una cantidad fija por todos los pechos reales y concejiles correspondientes a las personas que estuviesen dispuestas a morar allí trabajando a sus órdenes ${ }^{61}$. Es seguro que en la gestión de este

tille", partiendo de los procedimientos judiciales allí realizados a principios del siglo XVI. También J.M. MONSALVO ANTÓN. "Comunales de aldea, comunales de ciudad-y-tierra. Algunos aspectos de los aprovechamientos comunitarios en los concejos medievales de Ciudad Rodrigo, Salamanca y Ávila", El lugar del campesino. En torno a la obra de Reyna Pastor, Valencia, 2007, pp. 168-69, pone de relieve que los herederos intentaban controlar términos aldeanos a fin de "liberarse de las disciplinas del pastoralismo comuniego", siendo presa fácil los lugares poco poblados y despoblados. De todos modos, no siempre eran los fuertes los causantes de abusos, pues del mismo modo que la casuística puede ser muy variada, los autores podían proceder también del campesinado, aunque en estos casos los objetivos de los usurpadores eran muy diferentes.

59. AMC, leg. 190-2, f. 15r-v. Luego se hizo otra con un tercero.

60. AMC, leg. 198-2, f. 52v y 57v-58r. Por entonces se procedió a amojonar el término. Sin duda, tiene esto que ver con la repoblación que se estaba poniendo en práctica. AMC, leg. 198-3, f. 76r-90r.

61. En este caso se exceptuaban las monedas, AMC, leg. 194-1, f. 20r-v; y 194-4, f. 52r-55v. Otro acuerdo semejante se hizo el mismo año en relación a Las Tejas, 194-4, f. 28r-29v. Es muy probable que tras otros avenimientos también estén presentes intenciones colonizadoras semejantes. En la cercana tierra de Molina se documentan repoblaciones de despoblados realizadas por poderosos locales. Así lo indican M.E. CORTÉS RUIZ. Articulación jurisdiccional y estructura socioeconómica de la comarca de Molina de Aragón, p. 1067, y M. DIAGO. "Los términos despoblados en las comunidades de villa y tierra del Sistema Ibérico", p. 499-501. Concluye éste último que dichas repoblaciones mo- 
asunto contó mucho el peso específico del propietario y sus relaciones políticas, pero, en cualquier caso, se evidencia que las autoridades municipales conquenses, al igual que todos los poderes de la época, tenían muy claro el deseo de que la tierra estuviese bien poblada, como objetivo político explícito, y estaban dispuestos a utilizar la exención para que esto fuese así.

De este modo, con los años fue emergiendo otra opción consistente en el arrendamiento de términos por parte de las autoridades conquenses para que se pudiesen poblar, labrar y pacer. Ya hemos hablado acerca de estos arrendamientos, de modo que ahora nos limitaremos al simple recuerdo de los mismos, aunque sin olvidar que el desorden en su concesión debió ser bastante habitual. Una vez más intervenían las relaciones políticas y las conveniencias, pero conjugándose con el objetivo estratégico de tener la tierra habitada y productiva, paralelamente a la consolidación del grupo dominante. En todo caso, vemos que el concejo ciudadano recurrió a varias vías mediante las cuales se podía impulsar la colonización de lugares abandonados, siendo protagonistas tanto señores, beneficiarios de los avenimientos fiscales, como grupos de campesinos.

Sin embargo, la problemática repobladora que estamos viendo no puede ser más contradictoria, pues dada la fuerte impronta que ciertos notables tenían en los despoblados, así como la propensión de muchos de ellos a la usurpación, la ciudad tenía que precaverse para no sufrir deterioro en su jurisdicción. En este sentido, una disposición del año 1500, al tiempo que autorizaba las mencionadas colonizaciones poniendo en vigor, a tal fin, ejidos, dehesas, etc., pero excluyendo de tales arriendos a los individuos que allí estuviesen hacendados e incluso impidiendo pagar pechos a sus renteros. Se trataba de impedir la consolidación de nuevos vecinos que estuviesen totalmente sometidos a la voluntad de los señores y evitar que el lugar quedase totalmente en manos de un propietario ${ }^{62}$. Es indudable que la expansión agraria del siglo XV y la consecuente colonización de despoblados suscitaba un verdadero reto a la capacidad de organización y supervisión del territorio que era inherente al señorío concejil de la ciudad.

El carácter verdaderamente confuso y contradictorio que presenta todo lo referente a estos espacios despoblados y, en particular, a su revitalización, se pone de manifiesto cuando se mira hacia los obstáculos que se oponían a las iniciativas repobladoras. Por ejemplo, ya entrado el siglo XVI un documento nos indica que en Verdelpino, cerca de Cuenca, Sancho de Jaraba y Luis de Herriega, hacendados en el lugar, se oponían con firmeza a que cinco vecinos procedentes del inmediato señorío de Valdecabras se instalasen allí de manera definitiva. La autoridad concejil había reconocido su avecindamiento y el paso que a continuación se iba a dar

\footnotetext{
linesas se hicieron para impedir que el Común de la Tierra controlase determinadas dehesas y pastos. Hay que tener en cuenta que dicho Común consiguió hacerse con el dominio de no pocos despoblados.

62. AMC, leg. 65-2, 65-3, 44-3. Es lo que M. DIAGO ha llamado pseudorrepoblaciones en su artículo "Los términos despoblados en las comunidades de villa y tierra del Sistema Ibérico", p. 50. No obstante, unos años antes se había impedido a los renteros introducir en los pastos de los despoblados otro ganado que no fuese el de labor, a menos que se avecindasen en el lugar. J.M. SÁNCHEZ BENITO. "Territorio y conflicto en el ámbito jurisdiccional de Cuenca", pp. 110-11.
} 
consistía en señalarles solares, así como dehesa boyal; pero los citados propietarios, cuyo fin no era otro que reclamar la posesión de todo el término y el señorío del mismo, alegaban toda clase de argumentos para impedirlo ${ }^{63}$. Los intereses en liza no podían estar más claros: a) la ambición de los herederos en el sentido que acabamos de indicar, b) la necesidad de los inmigrados ansiando encontrar tierra cultivable, y c) la política de la ciudad para evitar la pérdida de territorios. Sin embargo, el ejemplo que aporta el despoblado de Villaverde conjuga de manera bien distinta estos mismos factores. Allí el cabildo catedralicio traía renteros, construía casas para ellos y les impulsaba a roturar nuevas tierras ${ }^{64}$. Pareciera contradictorio con respecto a lo anterior, pero los objetivos de todas las partes implicadas son los mismos.

En Mezquitas lo que ocurrió es que cuando empezaron a llegar labriegos para establecerse, el señor de la villa limítrofe, Valverde, se lo impidió por todos los medios, forzándoles a enajenarle las parcelas que hubiesen abierto en lo lleco y usando la violencia contra ellos e incluso contra los caballeros de la sierra. En este caso, por iniciativa del mencionado señor de Valverde se desarrollaban roturaciones encaminadas a hacerse con el control del término. Otras veces el problema consistía en que la ocupación de los baldíos por parte del poderoso allí instalado había adquirido tal dimensión que no quedaba literalmente tierra que roturar. Se comprende perfectamente que el concejo ciudadano diese su apoyo a los colonizadores de Yémeda cuando reclamaban tierra cultivable debido a que ciertos señores de la comarca habían usurpado casi toda la disponible. Era un caso evidente de colisión de dos iniciativas, la campesina, que el concejo respalda para afianzar su jurisdicción, y la impulsada por nobles cercanos con una finalidad exactamente contraria a los intereses conquenses ${ }^{65}$. Efectivamente, el concejo de la ciudad se adaptaba a la coyuntura secular alcista respaldando la colonización de ciertos despoblados. Con ello daban respuesta a las necesidades de tierra de los campesinos -que no por ello adquirían la propiedad de los terrenos roturados-, pero lo que resultaba más interesante para las autoridades es que al humanizar dichos espacios favorecían su control desde la ciudad. De todas formas, no conviene exagerar la iniciativa concejil en este aspecto $^{66}$.

Los inmigrantes que llegaban a los despoblados procedían de señoríos comarcanos -Monteagudo, La Ventosa, Valdecabras, Cañaveras, etc.- o de la vecina jurisdicción de Huete, así como también de la propia tierra conquense, y se desplazaban escasos kilómetros desde su punto de origen. Buscaban, tal como hemos

63. AMC, leg. 64-2.

64. AMC, leg. 44-3.

65. AMC, leg. 64-1; AGS, RGS, 1494-X, f. 302. Con respecto a Mezquitas, AMCu, leg. 67-3. Menciona lo ocurrido en este último lugar M. DIAGO. "Los términos despoblados en las comunidades de villa y tierra del Sistema Ibérico", pp. 474 y 505-06. También J.I. ORTEGA CERVIGÓN. La acción política y la proyección señorial de la nobleza, pp. 636-37.

66. C.M. VERA YAGÜE. Territorio y población en Madrid y su tierra en la Baja Edad Media. La señorialización del espacio madrileño y la repoblación concejil "antiseñorial" en los siglos XIV a XVI. Madrid, 1999. El propio título de la obra indica que los procesos repobladores de la tierra de Madrid se justifican como fruto de una política concejil definida y encaminada a frenar la presión señorial. 
visto, terrenos para cultivar, sea como renteros o bien arriesgándose a roturar, y es natural que muchos siguiesen conservando intereses e incluso casa en la localidad de partida. Lógicamente, para ellos era un obstáculo muy importante la oposición que a estos movimientos podían ofrecer los titulares de los señoríos de origen. No era demasiado raro que les impidieran el disfrute de los bienes que en ellos mantenían, a pesar de que la política regia sobre esta cuestión estuvo muy clara durante toda la etapa Trastámara y había pragmáticas que prohibían expresamente estas actitudes ${ }^{67}$.

Hasta ahora hemos insistido mucho en las acciones emprendidas por los poderosos y se han puesto de manifiesto los intereses contradictorios que, además de ellos, esgrimen tanto el órgano de poder ciudadano como los labriegos necesitados de tierra que estaban dispuestos a moverse. Solo que las cosas no acaban aquí, documentos tardíos nos presentan a un regidor de Arrancacepas quejándose porque los vecinos de su aldea eran prendados cuando se aprovisionaban de madera en el término cercano de Castillo de Albaráñez e igualmente cuando iban con sus cabras. Había allí un hombre llamado Alonso Moreno que decía haber repoblado el lugar y cuyos criados ejecutaban las prendas. Este individuo argumentando que había más de cinco vecinos consiguió que se respetase la dehesa boyal y además decía tener licencia conquense para agrandarla. Como es lógico, todo esto suponía una limitación para las aldeas próximas, pues hasta entonces no tenían límite para utilizar aquel término. Es indudable que la proliferación de despoblados favoreció a las comunidades aldeanas y, como sabemos, sus concejos se aprestaron hasta donde pudieron a defender las posibilidades que se les abrían. Por lo tanto, en el lugar que estamos comentando se desencadenó pleito y el debate jurídico terminó centrándose en la veracidad de la colonización. Se demostró que Moreno había avecindado allí a familiares suyos todavía presentes en su lugar de origen y la verdad es que todo parecía ficticio. Naturalmente, nada tiene que ver este asunto con las conductas e intereses de los grandes propietarios ciudadanos. Ahora de lo que se trata es de un campesino, desde luego acomodado y localmente influyente, que contando con criados, parentela y cierta influencia en la zona, no buscaba otra cosa que beneficiarse lo más posible de las posibilidades de roturación, pasto y aprovechamiento montaraz. Vemos pues que las contradicciones derivadas de los despoblados son muchas y en ellas salen a relucir agricultores con recursos suficientes como para expandirse más allá de las estrecheces de su pueblo de nacimiento, así como -con intereses contrarios- los aldeanos de los lugares inmediatos a los despoblados ${ }^{68}$.

67. AMC, leg. 6-15; 5-52; AGS, RGS 1492-XI, f. 25 у 203.

68. Otro caso de repoblación falsa algo distinto se detecta en Arguisuelas por las mismas fechas de principios del siglo XVI. El procurador de la tierra protestaba porque habían llegado gentes que sin fijar su residencia en el lugar y sin avecindarse disfrutaban de los comunales. AMC, leg. 64-3 y 75-1. 


\section{CONCLUSIÓN}

Hace unos años se explicó el fenómeno de los despoblados en el ámbito de Cuenca, señalando que se trataba de una reestructuración de la tierra en términos de preseñorialización ${ }^{69}$, con lo cual el foco se concentraba casi exclusivamente en la élite ciudadana propietaria. No negaremos la importancia de este grupo social en todo lo que se refiere a nuestro tema, pero en las páginas precedentes hemos ido encontrando diferentes intereses, cuyos ojos estaban puestos en las posibilidades que ofrecían los términos yermos. En una rápida enumeración cabe recordar los siguientes:

a. Los grandes herederos de la ciudad, así como también los nobles titulares de los señoríos comarcanos, ansiando unos y otros hacerse con el control de esta clase de espacios.

b. Por otra parte, las aldeas limítrofes, representadas por sus concejos, que ven en ellos una vía de expansión de su actividad económica.

c. Los campesinos más acomodados y con mayores posibilidades para roturar y proyectarse sobre su entorno.

d. El concejo urbano, que por fuerza tenía que preocuparse por la integridad de su espacio jurisdiccional y, al mismo tiempo, gestionar la práctica de los usos comunales.

e. En un plano totalmente distinto se ha visto que el debate en torno a dichos términos contribuyó de manera muy especial a la definición del Común de la Tierra como entidad organizada.

Salta a la vista que el alfoz de una ciudad como Cuenca, sometido al señorío colectivo que representaba su concejo, no era una mera proyección del centro de poder urbano sino que, en las condiciones de expansión económica y demográfica propias del siglo XV, daba lugar al encuentro -frecuentemente tenso-de múltiples intereses.

Sin duda, no podremos prescindir de los factores geográficos y, en particular, la naturaleza montuosa del espacio conquense. Allí surgieron en la repoblación plenomedieval multitud de lugares para aprovechar los terrenos cultivables salpicados en puntos favorables junto a los cursos de agua. Con el paso del tiempo, algunos de estos pueblos lograron consolidarse, mientras que otros no superaban unos niveles demográficos y productivos muy bajos. De esta manera, al norte y al sur de la tierra -sexmos de Arcas y Altarejos, y el septentrional de la Sierrala estructura de poblamiento fue adquiriendo una clara jerarquización a partir de ciertos núcleos principales, a la vez que en los territorios centrales las diferencias entre las aldeas eran menores, siendo todas considerablemente modestas. En estas condiciones la estructura de poblamiento, integrada por tan abundantes núcleos, fue desarrollando una continua rectificación a fin de adaptarse a las posibilida-

69. J.A. JARA FUENTE. Concejo, poder y élites, p. 325. 
des del medio ${ }^{70}$, así como a los diversos intereses en liza y, en fin, a las sucesivas condiciones históricas. De esta manera el nivel inferior de dicha estructura evolucionó de una manera especialmente inestable, dando lugar a las trayectorias intermitentes que tantas veces hemos encontrado en las páginas anteriores.

Siendo esto así, el desarrollo de la propiedad agraria de los ciudadanos conquenses condujo a la formación de sólidos heredamientos en los más diversos puntos de la tierra. Cuando esto ocurría en los lugares que formaban parte del mencionado nivel interior, entonces los herederos allí afincados no encontraban ningún contrapeso y la escasa actividad local se centraba únicamente en la explotación de sus fincas y, en definitiva, en su iniciativa. Se comprende muy bien que en esta evolución proliferasen usurpaciones y abusos, principalmente por parte de propietarios de mayor relieve cuya aspiración consistía en formar un término redondo, ajeno a los usos comunales.

Ya ha quedado indicado que los lugares que se vaciaron de manera definitiva a partir de la Baja Edad Media no son muchos en la tierra conquense, pero eso no impide que califiquemos el proceso descrito como una verdadera adaptación, mediante la cual el poblamiento resultante de los primeros tiempos se fue adecuando de manera selectiva a las sucesivas coyunturas y a la tendencia dominante en dicha época, claramente encaminada hacia la concentración de la población.

\section{BiBLIOGRAFÍA}

CABAÑAS, M.D. "La reforma municipal de Fernando de Antequera en Cuenca", $I^{o}$ Simposio Internacional de Historia de Cuenca. Cuenca y su territorio en la Edad Media, 1982.

CABRERA MUÑOZ, E. "Población y poblamiento, historia agraria, sociedad rural, en la Historia Medieval de España. Un balance historiográfico (19681998)", XXV Semana de Estudios Medievales. Estella, Pamplona, 1999.

CABRILlANA, N. "Los despoblados en Castilla la Vieja”, Hispania, 31 (1971).

Censo de 1787 "Floridablanca". Cuenca, Instituto Nacional de Estadística, Madrid, 1987

CHACÓN GÓMEZ-MONEDERO, F.A., CARRASCO, M.T., SALAMANCA, M. Libros de actas capitulares de la Catedral de Cuenca, II (1418-22), Cuenca, 2008.

CLEMENTE RAMOS, C. "Martín Sancho (siglos XIV-XVI). Un despoblado bajomedieval en la tierra de Medellín”, Hispania LXVI/223 (2006).

70. Hace unos años E. CABRERA señalaba de manera general la falta de idoneidad de la red de poblamiento creada en la repoblación, desembocando en un hábitat mucho más concentrado, "sin duda más realista en relación con las posibilidades del territorio". "Población y poblamiento, historia agraria, sociedad rural, en la Historia Medieval de España. Un balance historiográfico (1968-1998)", XXV Semana de Estudios Medievales. Estella. Pamplona, 1999, p. 703. 
CORTÉS RUIZ, M.E. Articulación jurisdiccional y estructura socioeconómica de la comarca de Molina de Aragón a lo largo de la Baja Edad Media. Tesis doctoral Universidad Complutense de Madrid, 2000.

DIAGO, M. "Los términos despoblados en las comunidades de villa y tierra del Sistema Ibérico castellano a finales de la Edad Media", Hispania 178 (1991).

DÍAZ LEÓN, A.M., GÓMEZ BRAVO, M. y MARTÍNEZ MARTÍN. I, “El despoblado medieval de La Golosa (Berninches, Guadalajara). I campaña arqueológica (1991)", Wad al Hayara 20 (1993).

GUERRERO NAVARRETE, Y. y SÁNCHEZ BENITO. J.M. Cuenca en la Baja Edad Media: un sistema de poder urbano. Cuenca, 1994.

GESTEIRO ARAUJO, M. y VICENTE LEGAZPI. M.L. "La población de la diócesis de Cuenca a mediados del siglo XVIII", Lope de Barrientos. Seminario de Cultura 4 (2011).

JARA FUENTE, J.A. Concejo, poder y élites. La clase dominante en Cuenca en el siglo XV. Madrid, 2000.

—. "'Que memoria de onbre non es en contrario': usurpación de tierras y manipulación del pasado en la Castilla urbana del siglo XV", Studia Historica. Historia Medieval 20-21 (2002-03).

-. "Facing the depredations and fighting the predators. Urban Castile and the defense of municipal jurisdiction in the Late Middle Ages", Imago Temporis. Medium Aevum I (2007).

LARRAÑAGA MENDÍA, J. Cuenca. Guía Larrañaga. Cuenca, 1966.

LORENZO PINAR, F.J. “Términos redondos y despoblamiento en Ávila al inicio de la Edad Moderna. Aproximación histórica”, Studia Zamorensia 2a etapa, VI (2002).

MADOZ, P. Diccionario geográfico-estadístico-histórico de España y sus posesiones de Ultramar. Castilla-La Mancha. Valladolid, (edición facsímil) 1987.

MOLENAT, J.-P. "Une mutation du paisaje rural: villages désertés en Nouvelle Castille, XIIe-XVIe siècles", Le paisaje rural: realités et representations. $X$ Colloque des historiens médiévistes, 1979.

—. Campagnes et Monts de Tolède du XIIème au XVème siècle. Madrid, 1997.

MONSALVO ANTÓN, J.M. "Las dos escalas de la señorialización nobiliaria al sur del Duero: concejos de villa y tierra frente a señorialización 'menor' (Estudio a partir de casos del sector occidental: señoríos abulenses y salmantinos”, Revista d'Historia Medieval 8 (1997).

—. "Comunales de aldea, comunales de ciudad-y-tierra. Algunos aspectos de los aprovechamientos comunitarios en los concejos medievales de Ciudad Rodrigo, Salamanca y Ávila”, El lugar del campesino. En torno a la obra de Reyna Pastor, Valencia, 2007.

ORTEGA CERVIGÓN, J.I. La acción politica y la proyección señorial de la nobleza territorial en el obispado de Cuenca durante la Baja Edad Media. Tesis doctoral Universidad Complutense de Madrid, 2006. 
REGLERO DE LA FUENTE, C. "Los despoblados bajomedievales en los Montes de Torozos: jerarquización del poblamiento y coyuntura económica”, Edad Media. Revista de Historia 1 (1998).

SÁNCHEZ BENITO, J.M. Las tierras de Cuenca y Huete en el siglo XIV. Historia económica. Cuenca, 1994.

—. "Territorio y conflicto en el ámbito jurisdiccional de Cuenca (Época de los Reyes Católicos)", Espacio, Tiempo y Forma 9 (1996).

—. "Una aldea realenga y su concejo en tiempos de los Reyes Católicos: Fuentes, tierra de Cuenca", Historia, Instituciones, Documentos 32 (2005).

-. Ciudad, territorio y poder: Huete y sus aldeas en el siglo XV. Cuenca, 2006.

_. "Sobre la organización de los territorios concejiles al sur del Sistema Central: ciudades y aldeas en los siglos XIV y XV", La Historia peninsular en los espacios de frontera: las "Extremaduras históricas" y la "Transierra" (siglos $X I-X V)$. Cáceres-Murcia, 2012.

—. "Violencia y pugna política. Estudio de sus repercusiones en el mundo urbano a través del caso de Cuenca (siglo XV)", Studia Historica. Historia Medieval 30 (2012).

SÁNCHEZ PABLOS, A.C. "La fiscalidad municipal en la tierra de Castilla en el siglo XV: el pecho de San Miguel en el territorio de Cuenca", Fiscalidad, sociedad y poder en las ciudades castellanas de la Baja Edad Media. Madrid, 2006.

VERA YAGÜE, C.M. Territorio y población en Madrid y su tierra en la Baja Edad Media. La señorialización del espacio madrileño y la repoblación concejil "antiseñorial” en los siglos XIV a XVI. Madrid, 1999.

Fecha de recepción del artículo: junio 2013

Fecha de aceptación y versión final: septiembre 2013 
